\title{
Basal shear stress of the Ross ice streams from control method inversions
}

\author{
Ian Joughin ${ }^{1}$ \\ Jet Propulsion Laboratory, California Institute of Technology, Pasadena, California, USA
}

Douglas R. MacAyeal

Department of Geophysical Sciences, University of Chicago, Chicago, Illinois, USA

Slawek Tulaczyk

Earth Sciences Department, University of California, Santa Cruz, California, USA

Received 30 December 2003; revised 23 June 2004; accepted 16 July 2004; published 24 September 2004.

[1] We used control method inversions to determine the basal shear stress beneath the Ross ice streams where new high-resolution velocity data sets have recently become available. The inversion algorithm was adapted from an earlier viscous bed algorithm to allow solution for the basal shear stress corresponding to a weak plastic bed. We performed several experiments using synthetic data to determine the quality of the inversions. These experiments indicate that with high-quality surface elevation data (e.g., errors $<5 \mathrm{~m}$ ), the inversions are relatively robust with respect to errors in ice flow velocity and bed topography. The inversions are consistent with seismic and borehole observations and indicate that the Ross ice streams lie atop a bed that is nearly everywhere weak. In contrast, the tributaries feeding these ice streams overlie alternating patches of strong and weak bed. INDEX TERMS: 1827 Hydrology: Glaciology (1863); 9310 Information Related to Geographic Region: Antarctica; 0933 Exploration Geophysics: Remote sensing; 1640 Global Change: Remote sensing; 3260 Mathematical Geophysics: Inverse theory; KEYWORDS: glaciology, Antarctica, ice streams, remote sensing

Citation: Joughin, I., D. R. MacAyeal, and S. Tulaczyk (2004), Basal shear stress of the Ross ice streams from control method inversions, J. Geophys. Res., 109, B09405, doi:10.1029/2003JB002960.

\section{Introduction}

[2] Large areas beneath the West Antarctic Ice Sheet (WAIS) rest on weak unconsolidated sediments (till) [Blankenship et al., 1986; Kamb, 2001] believed to enable the relatively fast motion of the Ross ice streams (Ice Streams A, B, C, D, E, and F, also called Mercer, Whillans, Kamb, Bindschadler, MacAyeal, and Echelmeyer). These ice streams are remarkable in that their driving stresses are roughly an order of magnitude less than typical outlet glaciers values, yet their flow speeds fall within the range of typical outlet glacier speeds [Alley et al., 1986]. Understanding the frictional properties of subglacial till is thus important to predicting the future contribution of WAIS to sea level. In addition, many of the northern hemisphere ice sheets during the last glacial are believed to have flowed over soft (e.g., unconsolidated sediments) beds, which may have reduced their response time to rapid climate change

\footnotetext{
${ }^{1}$ Now at Polar Science Center, Applied Physics Laboratory, University of Washington, Seattle, Washington, USA.

Copyright 2004 by the American Geophysical Union. 0148-0227/04/2003JB002960\$09.00
}

[Clark et al., 1999]. As the last remaining marine-based ice sheet, WAIS provides a "natural laboratory" with which to understand the processes in former ice sheets that led to instabilities and rapid response to climatic conditions.

\subsection{Background}

[3] The portion of WAIS that drains into the Ross Sea Embayment varies its discharge on a number of timescales. Since the Last Glacial Maximum, the grounding line has retreated by distances of up to $1300 \mathrm{~km}$ [Conway et al., 1999]. Over the last millennium, flow stripes preserved in the surface of the Ross Ice Shelf record a history of significant variability in ice stream discharge [Fahnestock et al., 2000] with the best known example being the shutdown of the lower region of Ice Stream C about 150 years ago [Retzlaff and Bentley, 1993]. Over the last two decades, Ice Stream B has decelerated by $23 \%$ (1974-1997) [Joughin et al., 2002]. Over much shorter timescales, Ice Streams B and D have exhibited diurnal variation with significant changes in velocity occurring over periods as short as several minutes [Anandakrishnan et al., 2003; Bindschadler et al., 2003]. The longer-term variations have had a direct impact on sea level. For example, the stagnation of Ice Stream $\mathrm{C}$ and slowdown 
of Ice Stream B have caused this region to switch from a negative (thinning) to positive (thickening) mass balance [Joughin and Tulaczyk, 2002].

[4] The key feature thought to make this variability possible is the presence of a weak melted bed [Alley et al., 1986]. By "weak" we mean that the till can support only a fraction of the basal shear stress $(\mathrm{O}(10) \mathrm{kPa})$ that could be supported by a "strong" ice-crystalline-bedrock interface $(\mathrm{O}(100) \mathrm{kPa})$. The strength of basal till is extremely sensitive to effective pressure and water content [Tulaczyk et al., 2000]. It is believed that this sensitivity may cause the till to act as a "switch" that modulates ice stream motion and yields much of the observed flow variability. In the absence of significant resistance from a weak bed, ice stream shear margins can support much of the driving stress [Whillans and van der Veen, 1997]. In addition, the driving stress may be balanced, in part, by the presence of "sticky spots" [Alley, 1993]. The location and strength of these spots may be a significant factor in regulating ice stream flow.

[5] Reflection seismology measurements were first used to infer the presence of a layer of dilatant till beneath Ice Stream B [Blankenship et al., 1986]. Subsequent boreholes have yielded samples of till beneath Ice Streams B, C, and D [Kamb, 1991, 2001]. Aero-geophysical and seismic measurements have revealed a number of sedimentary basins lying upstream of the ice streams that provide a likely source for the till [Anandakrishnan et al., 1998; Bell et al., 1998; Blankenship et al., 2001]. These basins also provide troughs through which the tributaries feeding the ice streams flow [Joughin et al., 1999; Studinger et al., 2001].

\subsection{Aims of the Present Study}

[6] While seismic measurements and borehole samples can reveal an underlying layer of till, these measurements are unable to detect the regional distribution of till and sticky spots. Inverse methods developed to estimate shear stress from ice velocity, thickness, and elevation data have been applied to ice velocity data from Ice Stream E [MacAyeal, 1992; MacAyeal et al., 1995; Thorsteinsson et al., 2004] and the northeast Greenland Ice Stream [Joughin et al., 2000]. Here we extend the control method approach [MacAyeal, 1992], originally designed for a viscous deforming bed [Alley et al., 1986], to yield a direct inversion for the basal shear stress of the till beneath ice streams.

\section{Methods}

[7] We determine basal shear stress, $\tau_{b}$, using a control method inversion technique for ice streams developed by MacAyeal [1992, 1993]. The inversions are constrained by interferometric synthetic aperture radar (InSAR) and LandSAT feature-tracking data [Bindschadler et al., 1996; Joughin et al., 2002]. Earlier approaches employed an assumption that basal shear stress is a linear function of the depth-averaged velocity as proposed by Alley et al. [1986]. We relax this assumption in this study to also address a plastic bed rheology. The following subsections review the basic theory and method and describe the algorithmic details of the control method inversion.

\subsection{Forward Ice Stream Model}

[8] The equations that approximate large-scale ice stream flow over a weak bed are [MacAyeal, 1989]

$$
\begin{aligned}
& \frac{\partial}{\partial x}\left(2 \nu H\left(2 \frac{\partial u}{\partial x}+\frac{\partial v}{\partial y}\right)\right)+\frac{\partial}{\partial y}\left(\nu H\left(\frac{\partial u}{\partial y}+\frac{\partial v}{\partial x}\right)\right) \\
& \quad-\tau_{b, x}-\rho g H \frac{\partial z_{s}}{\partial x}=0 \\
& \frac{\partial}{\partial y}\left(2 \nu H\left(2 \frac{\partial v}{\partial y}+\frac{\partial u}{\partial x}\right)\right)+\frac{\partial}{\partial x}\left(\nu H\left(\frac{\partial u}{\partial y}+\frac{\partial v}{\partial x}\right)\right) \\
& \quad-\tau_{b, y}-\rho g H \frac{\partial z_{s}}{\partial y}=0,
\end{aligned}
$$

where $u$ and $v$ are the $x$ - and $y$-components of velocity, $x$ and $y$ are the Cartesian coordinates defining the horizontal plane, $\rho$ is the density of ice, $g$ is the acceleration due to gravity, $z_{s}$ is the surface elevation, $H$ is the ice thickness, $\tau_{b, x}$ and $\tau_{b, y}$ are the components of the basal shear stress, and $v$ is the effective viscosity given by

$$
\nu=\frac{E^{-1 / n} B}{2\left(\left(\frac{\partial u}{\partial x}\right)^{2}+\left(\frac{\partial v}{\partial y}\right)^{2}+\frac{1}{4}\left(\frac{\partial u}{\partial y}+\frac{\partial v}{\partial x}\right)^{2}+\frac{\partial u}{\partial x} \frac{\partial v}{\partial y}\right)^{(n-1) / 2 n}}
$$

In the expression for effective viscosity, $B$ is the depthaveraged flow law rate factor and $n$ is the flow law exponent [Paterson, 1994]. The flow law is often alternately parameterized with $A=B^{-n}$ [Thomas et al., 1980]. The parameter $A(B)$ is often scaled by a strain rate enhancement factor, $E\left(E^{-1 / n}\right)$, to account for effects such as strain softening. Throughout the remainder of this paper we use the common assumption that $n=3$ [Paterson, 1994].

[9] For a viscous deforming bed model (e.g., like that used in earlier inverse studies by MacAyeal [1992]), the velocity-dependent basal shear stress is given by

$$
\begin{aligned}
& \tau_{b, x}=\beta^{2} u \\
& \tau_{b, y}=\beta^{2} v
\end{aligned},
$$

where basal friction is represented by a squared coefficent, $\beta^{2}$, with the role of the square being to ensure a nonnegative value in the inversion process. This simple linear parameterization was used in earlier studies [MacAyeal, 1989]. Subsequent studies of till conditions, primarily involving actual till samples, suggest that the relationship between basal stress and velocity is not linear [Kamb, 1991, 2001; Tulaczyk et al., 2001]. An alternate parameterization for the basal shear stress is proposed:

$$
\begin{aligned}
& \tau_{b, x}=\alpha^{2} \tilde{u} \\
& \tau_{b, y}=\alpha^{2} \tilde{v}
\end{aligned}
$$

where the speed-independent magnitude of the the basal shear stress is determined by $\alpha^{2}$. With this parameterization, the direction is determined by the velocity through the direction vectors $\tilde{u}=\cos \theta$ and $\tilde{v}=\sin \theta$, where $\theta$ is the angle 
of the flow vector relative to the $x$ axis. Again, the role of the square is to ensure a positive coefficient. In this study, we invert only for $\alpha$ and let the velocity data determine the direction such that

$$
\begin{aligned}
& \tau_{b, x}=\alpha^{2} \tilde{u}_{d} \\
& \tau_{b, y}=\alpha^{2} \tilde{v}_{d}
\end{aligned}
$$

where $u_{d}$ and $v_{d}$ are determined by the direction of the measured velocities. While this parameterization gives a direct solution for the basal shear stress, it can be considered equivalent to a plastic bed with a distinct yield stress. Thus we refer to equations (4) and (5) as the plastic bed model throughout the remainder of this paper.

[10] We can also assume a more general form of a plastic bed, where the direction of the resistance is not constrained by velocity, either modeled or observed. In this case, we invert directly for $\tau_{b, x}$ and $\tau_{b, y}$ in equation (1). The other models yield a scalar amplitude for the basal shear stress. To facilitate comparison with the other models, we can compute

$$
\tau_{b}=\left[\begin{array}{ll}
\tau_{b, x} & \tau_{b, y}
\end{array}\right] \bullet\left[\begin{array}{c}
\tilde{u}_{d} \\
\tilde{v}_{d}
\end{array}\right]=\tau_{b, x} \tilde{u}_{d}+\tau_{b, y} \tilde{v}_{d}
$$

In this equation we assume that the true basal shear stress is aligned with the velocity vector, and thus discard the cross flow component of resistance, which may have served to improve the inversion by compensating for errors in the data. We refer to this solution as the vector plastic bed solution and use equation (6) to compute $\tau_{b}$ as a scalar for comparison with other bed parameterizations.

\subsection{Inversion Model}

[11] To invert the velocity data for $\tau_{b}$, we minimize the model-data misfit while enforcing the model physics as a constraint (e.g., the result is a valid solution to equation (1)). We begin with the plastic bed parameterization given by equation (5). The appropriate cost function for the plastic bed model is given by

$$
\begin{aligned}
J= & \int_{\Gamma} \int_{\Gamma} \frac{1}{2}\left\{\left(u-u_{d}\right)^{2}+\left(v-v_{d}\right)^{2}\right\} d x d y+\iint_{\Gamma} \lambda(x, y) \\
& \cdot\left\{\frac{\partial}{\partial x}\left(2 \nu H\left(2 \frac{\partial u}{\partial x}+\frac{\partial v}{\partial y}\right)\right)+\frac{\partial}{\partial y}\left(\nu H\left(\frac{\partial u}{\partial y}+\frac{\partial v}{\partial x}\right)\right)-\alpha^{2} \tilde{u}_{d}\right. \\
& \left.-\rho g H \frac{\partial z_{s}}{\partial x}\right\} d x d y+\iint_{\Gamma} \mu(x, y)\left\{\frac{\partial}{\partial y}\left(2 \nu H\left(2 \frac{\partial v}{\partial y}+\frac{\partial u}{\partial x}\right)\right)\right. \\
& \left.+\frac{\partial}{\partial x}\left(\nu H\left(\frac{\partial u}{\partial y}+\frac{\partial v}{\partial x}\right)\right)-\alpha^{2} \tilde{v}_{d}-\rho g H \frac{\partial z_{s}}{\partial y}\right\} d x d y
\end{aligned}
$$

where $\lambda$ and $\mu$ are components of the Lagrange multiplier vector

$$
\Lambda=\left[\begin{array}{l}
\lambda \\
\mu
\end{array}\right]
$$

used to enforce satisfaction of the model physics represented by equations (1) and (2) and where the domain of integration, $\Gamma$, is taken to be the domain over which the inversion is attempted.

[12] The variation of the functional given in equation (7) is given by

$$
\begin{aligned}
\delta J= & \int_{\Gamma} \int\left\{\left(\left(u-u_{d}\right)+\frac{\partial}{\partial x}\left(2 \nu H\left(2 \frac{\partial \lambda}{\partial x}+\frac{\partial \mu}{\partial y}\right)\right)\right.\right. \\
& \left.+\frac{\partial}{\partial y}\left(\nu H\left(\frac{\partial \lambda}{\partial y}+\frac{\partial \mu}{\partial x}\right)\right)\right) \delta u+\left(\left(v-v_{d}\right)\right. \\
& \left.+\frac{\partial}{\partial y}\left(2 \nu H\left(2 \frac{\partial \mu}{\partial y}+\frac{\partial \lambda}{\partial x}\right)\right)+\frac{\partial}{\partial x}\left(\nu H\left(\frac{\partial \lambda}{\partial y}+\frac{\partial \mu}{\partial x}\right)\right)\right) \delta v \\
& +\left(-\alpha^{2} \tilde{u}_{d}-\rho g H \frac{\partial z_{s}}{\partial x}+\frac{\partial}{\partial x}\left(2 \nu H\left(2 \frac{\partial u}{\partial x}+\frac{\partial v}{\partial y}\right)\right)\right. \\
& \left.+\frac{\partial}{\partial y}\left(\nu H\left(\frac{\partial u}{\partial y}+\frac{\partial v}{\partial x}\right)\right)\right) \delta \lambda+\left(-\alpha^{2} \tilde{v}_{d}-\rho g H \frac{\partial z_{s}}{\partial y}\right. \\
& \left.+\frac{\partial}{\partial x}\left(\nu H\left(\frac{\partial u}{\partial y}+\frac{\partial v}{\partial x}\right)\right)+\frac{\partial}{\partial y}\left(2 \nu H\left(2 \frac{\partial v}{\partial y}+\frac{\partial u}{\partial x}\right)\right)\right) \delta \mu \\
& \left.-2 \alpha\left(\lambda \tilde{u}_{d}+\mu \tilde{v}_{d}\right) \delta \alpha\right\} d x d y .
\end{aligned}
$$

An extremal for the functional given by equation (7) requires that the variation given by equation (8) equals zero. This condition is satisfied with respect to arbitrary variation of $\lambda$ and $\mu$ when the ice stream equations given by equation (1) are satisfied. Likewise, the variation of $J$ with respect to arbitrary variations of $u$ and $v$ is zero upon satisfaction of the adjoint equations (e.g., they are mathematically adjoint to equation (1)) for the Lagrange multipliers given by

$$
\begin{aligned}
& \frac{\partial}{\partial x}\left(2 \nu H\left(2 \frac{\partial \lambda}{\partial x}+\frac{\partial \mu}{\partial y}\right)\right)+\frac{\partial}{\partial y}\left(\nu H\left(\frac{\partial \lambda}{\partial y}+\frac{\partial \mu}{\partial x}\right)\right)=\left(u_{d}-u\right) \\
& \frac{\partial}{\partial y}\left(2 \nu H\left(2 \frac{\partial \mu}{\partial y}+\frac{\partial \lambda}{\partial x}\right)\right)+\frac{\partial}{\partial x}\left(\nu H\left(\frac{\partial \lambda}{\partial y}+\frac{\partial \mu}{\partial x}\right)\right)=\left(v_{d}-v\right)
\end{aligned}
$$

[13] The remaining term that needs to be satisfied for arbitrary variation $\delta \alpha$ is

$$
\iint_{\Gamma}\left\{-2 \alpha\left(\lambda \tilde{u}_{d}+\mu \tilde{v}_{d}\right) \delta \alpha\right\} d x d y=0 .
$$

There are several situations where this could occur. First, $\alpha$ (basal shear stress) could drop to zero. Alternately, if the data-model mismatch is zero everywhere, then $\lambda$ and $\mu$ will also be zero. The integral will also equal zero if the adjoint solution is orthogonal to the velocity vector at all points. Finally, the function $\alpha$ may be orthogonal to $\left(\lambda \tilde{u}_{d}+\mu \tilde{v}_{d}\right)$. In the latter two cases, the data may not exactly match the model but no further improvement can be achieved through variation of $\alpha$.

[14] For the viscous bed case, represented by equation (3), equations similar to equations (7) and (8) can be derived. In this case, the integral given by equation (10) is replaced with

$$
\iint_{\Gamma}-2 \beta(\lambda u+\mu v) \delta \beta d x d y=0,
$$


and the $\alpha^{2} \tilde{u}_{d}$ and $\alpha^{2} \tilde{v}_{d}$ terms in equation (8) are replaced with $\beta^{2} u$ and $\beta^{2} v$ [MacAyeal, 1993]. Likewise, for the vector plastic direct inverions for $\tau_{b, x}$ and $\tau_{b, y}$, the integral in equation (10) is replaced with

$$
\iint_{\Gamma}\left(-\lambda \delta \tau_{x}-\mu \delta \tau_{y}\right) d x d y=0
$$

where $\delta \tau_{x}$ and $\delta \tau_{y}$ are now two independent parameters to be varied.

[15] In order to complete the inversion, we need a way to satisfy equation (10) (or similarly equations (11) or (12) for the alternate rheologies). Let the basal shear stress and corresponding variation, $\delta \alpha$, be expressed as

$$
\begin{gathered}
\alpha=\sum_{i=1}^{N} \alpha_{i} \phi_{i} \\
\delta \alpha=\sum_{j=1}^{N} \delta \alpha_{j} \phi_{j}
\end{gathered}
$$

where $\phi_{i}$ and $\phi_{j}$ are sets of $N$ basis functions that are able to represent $\alpha$ to the level of desired spatial resolution. Substitution of this function into equation (10) yields

$$
\sum_{i=1}^{N} \sum_{j=1}^{N} \iint_{\Gamma}\left\{-2 \alpha_{i} \phi_{i}\left(\lambda \tilde{u}_{d}+\mu \tilde{v}_{d}\right) \delta \alpha_{j} \phi_{j}\right\} d x d y=\left(\nabla_{\alpha} J\right)^{T} \cdot \delta \boldsymbol{\alpha}
$$

where

$$
\nabla_{\alpha} J=\left[\begin{array}{c}
\sum_{i=1}^{N} \iint_{\Gamma}\left\{-2 \alpha_{1} \phi_{1}\left(\lambda \tilde{u}_{d}+\mu \tilde{v}_{d}\right) \phi_{j}\right\} d x d y \\
\vdots \\
\sum_{i=1}^{N} \iint\left\{-2 \alpha_{N} \phi_{N}\left(\lambda \tilde{u}_{d}+\mu \tilde{v}_{d}\right) \phi_{j}\right\} d x d y
\end{array}\right]
$$

and

$$
\delta \boldsymbol{\alpha}=\left[\begin{array}{c}
\delta \alpha_{1} \\
\vdots \\
\delta \alpha_{N}
\end{array}\right]
$$

Equation (15) allows calculation of the gradient of $J$ with respect to the parameters, $\alpha_{i}$. At each iteration of the minimization algorithm, we obtain this gradient efficiently by only having to solve the adjoint equation once per iteration to determine $\nabla_{\alpha} J$. In an alternative approach, $2 N$ solutions of the ice stream equations would be required to obtain a finite difference evaluation for the gradient, $\nabla_{\alpha} J$. This allows the inversion to proceed as a relatively efficient down-gradient minimization of equation (7). A similar set of equations can be derived for the viscous and vector plastic cases based on equations (11) and (12), respectively.
[16] While we have described three parameterizations for $\tau_{b}$ (viscous, plastic, vector plastic), inversion with any of these parameterizations proceeds roughly in the same manner and yields the basal shear stress that provides a force balance consistent with the model given by equation (1). Force balance is achieved regardless of the assumed bed rheology. As a result, even though equation (3) applies to a viscous bed, $\beta^{2}$ is a free parameter, so force balance can be achieved even if the bed exhibits weak plastic rather than linear viscous behaviour. Thus the inversion results alone do not distinguish which is the most appropriate bed model.

\subsection{Inversion Implementation}

[17] We have implemented a finite element solution to the forward model specified by equation (1) using a finite element mesh varying from about 1 to $3 \mathrm{~km}$ in spatial resolution. This resolution is necessary to resolve strong shear at the margins. Since the model is only applicable to bed structure greater than a few ice thicknesses in spatial scale, there is no benefit to using a finer resolution mesh. Because of the nonlinearity introduced by the effective viscosity an iterative method of sucessive approximations is used to determine $\nu$ [MacAyeal, 1989]. A similar solution is used for the adjoint equations (equation (9)). Either kinematic (velocity) or dynamic (vertically integrated stresses) boundary conditions can be used for solution of equation (1). In this study we rely exclusively on kinematic boundary conditions since the data in Figure 1 allow us to specify velocity on all boundaries of the regions over which the inversions are desired.

[18] The inversion begins with an initial guess for the basal shear stress, which is used to solve the forward model. Next, the adjoint equations are solved using the result from the forward model and this result is used to determine $\nabla_{\alpha} J$. The current inverse solution is then updated with the addition of $C \nabla_{\alpha} J$, where $C$ is a constant that is selected to minimize the model/data misfit. Iterations of this procedure continue until one of the convergence criteria discussed previously has been met. In our implementation, convergence is assumed once the improvement in the model-data misfit for the last 10 iterations falls below a preset threshold.

[19] All bed models yield nearly identical basal shear stress distributions. There are large differences, however, in sensitivity to the basal shear stress parameterizations in the forward model. Since basal resistance increases with velocity in the viscous bed model, even a relatively poor initial guess of the basal drag coefficient, $\beta$, will often yield reasonable velocities. In constrast, with both plastic bed models there is no velocity feedback, so extreme velocity fluctuations can occur even for a relatively close initial guess. Thus when inverting either of the plastic bed models, we iterate first on the intitial guess ten or more times with the viscous inverson procedure. This result is then used as the initial guess for the plastic bed inversion, which greatly speeds convergence.

\section{Inversions With Synthetic Data}

[20] We performed several experiments using synthetic data to determine how well the inversion procedures are able to determine $\tau_{b}$. These experiments were based on 


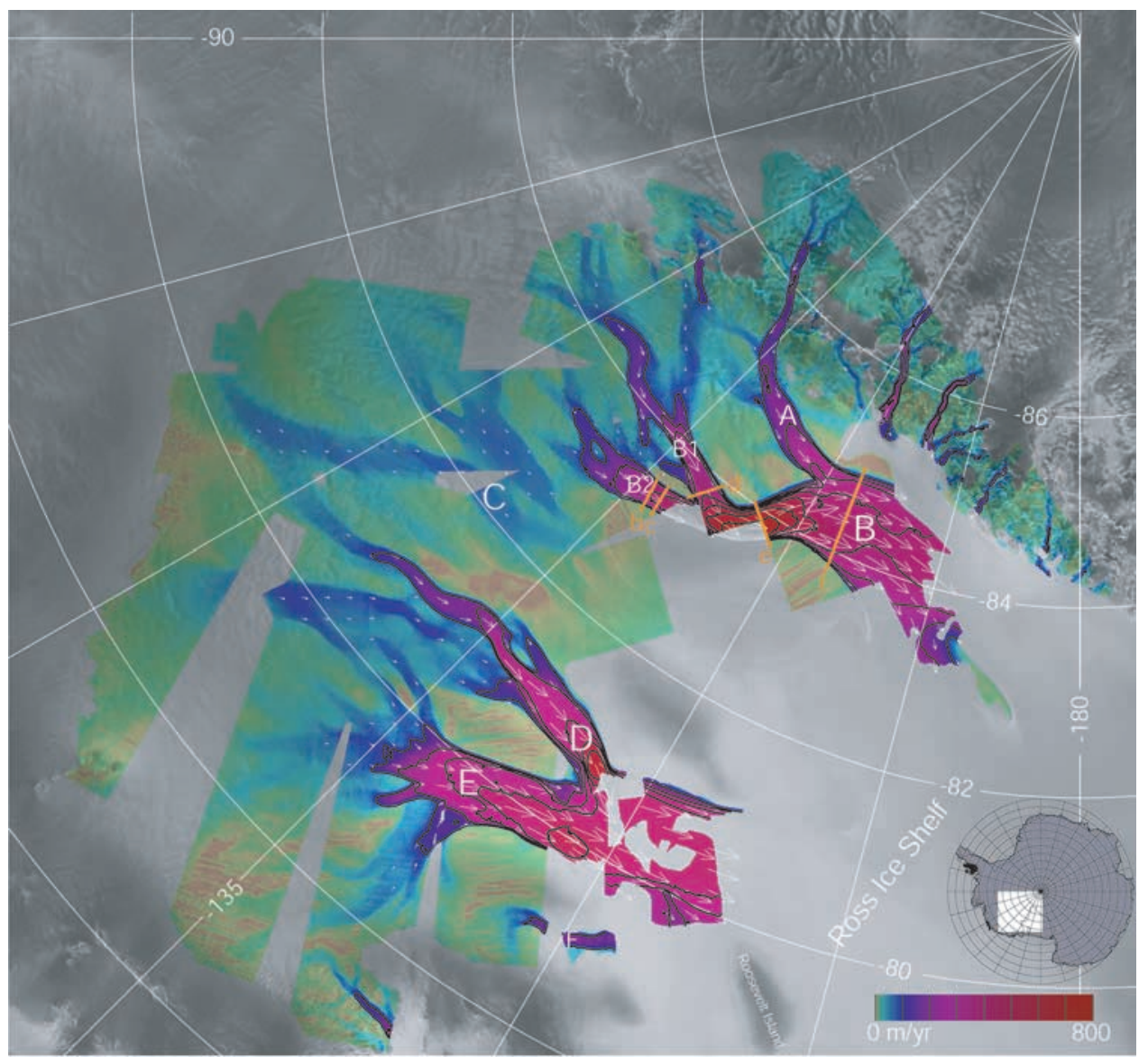

Figure 1. Ice flow speed (colors) [Joughin et al., 2002] over radar imagery from the RADARSAT Antarctic Mapping Project Mosaic [Jezek, 2002]. Flow speed at $100 \mathrm{~m} / \mathrm{yr}$ intervals is contoured with thin black lines. White vectors show subsampled velocity vectors in fast moving areas. Catchment boundaries for individual ice streams are plotted with thick black lines. Orange lines show the locations of profiles plotted in Figure 9.

velocities generated for a model ice stream using equations (1)-(3). To generate these synthetic data, we began by generating synthetic bed and surface topography for an ice stream that was $20 \mathrm{~km}$ wide at the upstream end, widening to $60 \mathrm{~km}$ at the downstream end (Figure 2). We used a simple 2-D model [Raymond, 1996, equation 35] to simulate an ice stream with centerline velocities of roughly $400 \mathrm{~m} / \mathrm{yr}$. We then inverted this simple estimate to obtain a basal shear stress distribution. Finally, we used this basal $\tau_{b}$ solution and the bed and surface topographies to simulate velocity using the full forward model. Figure 2 shows the model inputs and the synthetic velocity data.

\subsection{Sensitivity to Initial Condition}

[21] Our first set of experiments was designed to test the sensitivity of the inversions to the initial conditions and to examine the uniqueness of the solutions. To accomplish this, we used the exact data sets (e.g., surface, bed, velocity) from the forward model in the inversion. The finite element mesh used for the inversion was different from that used to generate the synthetic data sets. This difference introduced minor sampling differences.

[22] We experimented with four different initial conditions. For the first case we used $\tau_{b}$ from the forward model ("truth") as the initial condition. For the next experiment, we used the same $\tau_{b}$ but with noise added ("truth plus noise"). The noise was constructed to have only wavelengths of roughly $10 \mathrm{~km}$ and greater and the rms (root mean square) deviation of the noise was just over half that of the rms variation of the synthetic basal shear stress. For the third experiment, the initial guess was set to $50 \%$ of the driving stess (" $50 \%$ of $\tau_{d}$ "). In the fourth experiment, we used a constant value ("constant value") over the entire domain as the initial guess.

[23] The inversion attempts to minimize the performance measure, $J$, which is a measure of how well the model with the inverted basal shear stress matches the observed velocities. With the simulations, we can compare this metric against other statistics that evaluate how well the inversion actually determined the basal shear stress. For this purpose, we compute the mean, $\mu_{I-T}$, and standard deviation, $\sigma_{I-T}$, of the difference between the inversion (I) and truth (T). We use $\mu_{I-T}$ to assess biases in the inversion and $\sigma_{I-T}$ to evaluation random errors. We also include the crosscorrelation coefficient, $\rho$, between inversion and truth to help evaluate how well the inversion does at determing the spatial structure. Note since the model strictly applies only to the fast moving areas where there is little vertical shear 

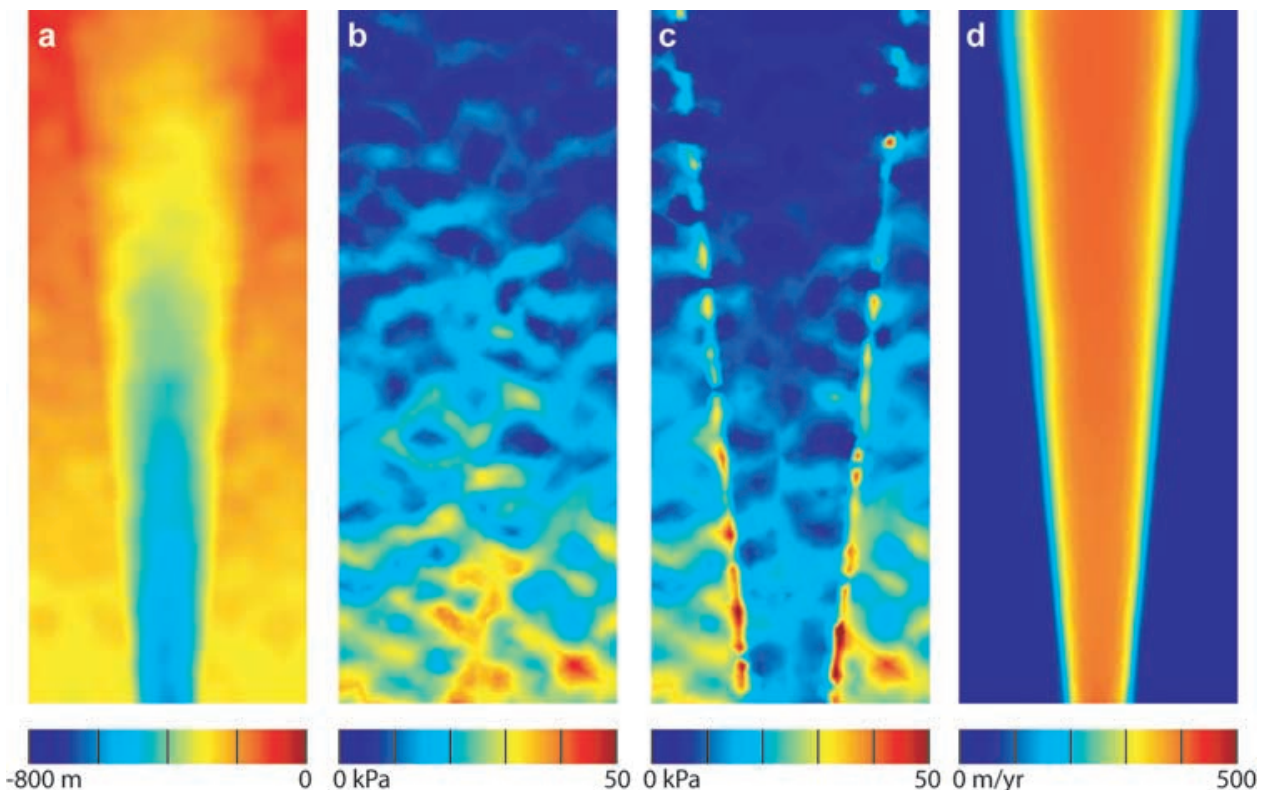

Figure 2. Synthetic data for inversion experiments. Forward model inputs (a) bed topography, $z_{b}$, (b) driving stress, $\tau_{d}$, (c) basal shear stress, $\tau_{b}$, and (d) forward model output velocity. The hypothetical ice stream is $60 \mathrm{~km}$ wide at the top and $20 \mathrm{~km}$ wide at the bottom.

[MacAyeal, 1989], we only evaluate these statistics for the main body of the ice stream (i.e., area moving faster than $300 \mathrm{~m} / \mathrm{yr}$ ).

[24] Figure 3 shows the difference between the known and the inverted $\tau_{b}$ for the viscous bed experiments. Statistics $\left(\mu_{I-T}, \sigma_{I-T}, \rho\right)$ for the initial-condition experiments are shown in Table 1 for all three bed models. As expected, the best result is achieved when "truth" is used as the initial condition. Some small differences still exist, which likely are caused by interpolation error. In contrast, both "truth plus noise" and "constant value" give signficantly poorer results (see Figure 3) in terms of matching the severalkilometer-scale structure of the basal shear stress, but yield reasonable values for the mean bed resistance. In particular, Figure $3 \mathrm{c}$ illustrates that the "truth plus noise" solution has a high degree of erroneous spatial structure, which is likely introduced by the structure of the noise in the intial condition. Even with the poor quality of this inversion, a good fit is achieved in terms of the velocity misfit, $J$.

[25] Without a priori knowledge of the basal resistance, the " $50 \%$ of $\tau_{d}$ " initial condition provides the best fit. This is likely because the basal shear stress, at least to some
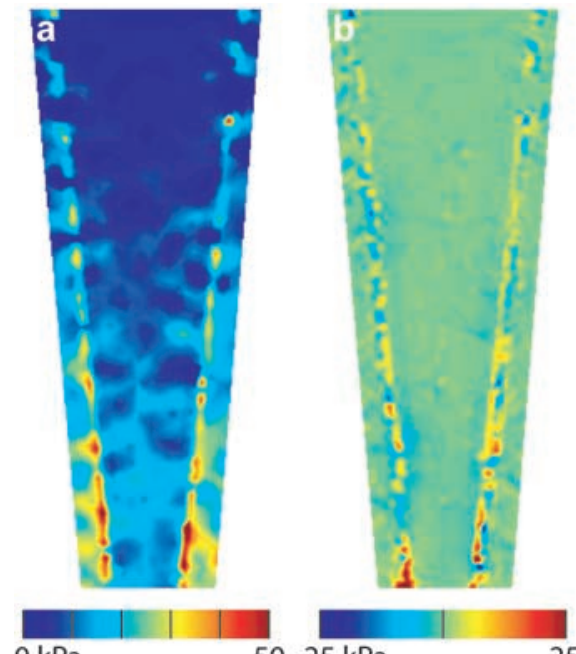

$0 \mathrm{kPa}$

$50-25 \mathrm{kPa}$

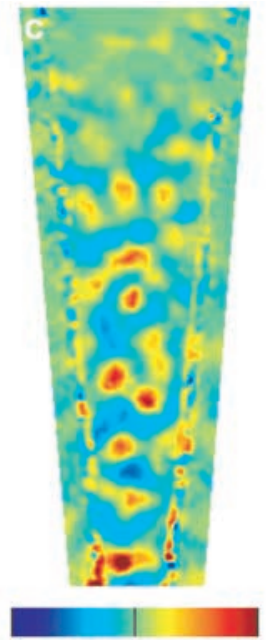

$25-25 \mathrm{kPa}$

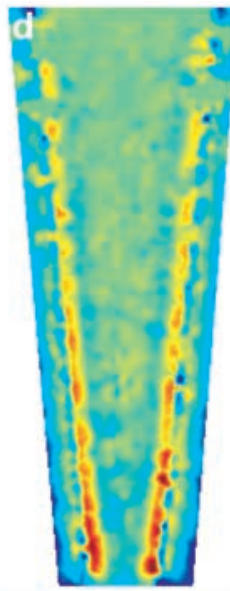

$25-25 \mathrm{kPa}$

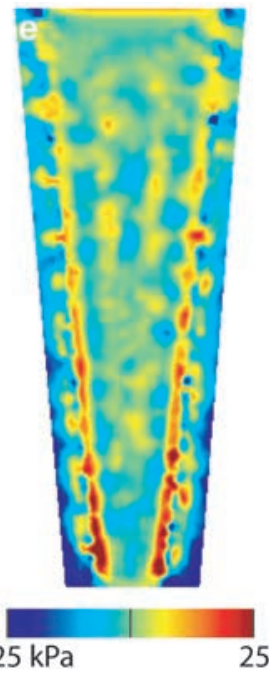

25

Figure 3. (a) Basal shear stress, $\tau_{b}$ used in forward model for initial condition experiments and differences between $\tau_{b}$ and viscous bed inversions for (b) "truth," (c) "truth plus noise," (d) "50\% of $\tau_{d}$," and (e) "constant value." 
Table 1. Inversion Results Using Noiseless Data With Four Different Initial Conditions ${ }^{\mathrm{a}}$

\begin{tabular}{|c|c|c|c|c|}
\hline \multirow[b]{2}{*}{ Result } & \multicolumn{4}{|c|}{ Initial Condition Experiment } \\
\hline & Truth & $\begin{array}{c}\text { Cruth Plu } \\
\text { Noise }\end{array}$ & $50 \%$ of $\tau_{d}$ & Constant Value \\
\hline \multicolumn{5}{|c|}{ Viscous Model, $\tau_{b, x}=\beta^{2} u ; \tau_{b, v}=\beta^{2} v$} \\
\hline$\sqrt{J}, \mathrm{~m} / \mathrm{yr}$ & 3 & 4.1 & 7.8 & 8.8 \\
\hline$\mu_{I-T}, \mathrm{kPa}$ & -0.2 & -0.1 & -0.7 & -0.6 \\
\hline$\sigma_{I-T}, \mathrm{kPa}$ & 0.6 & 6.4 & 2 & 3.5 \\
\hline$\rho$ & 0.99 & 0.60 & 0.93 & 0.78 \\
\hline \multicolumn{5}{|c|}{ Plastic Model, $\tau_{b, x}=\tau^{2} \tilde{u} ; \tau_{b, y}=\tau^{2} \tilde{v}$} \\
\hline$\sqrt{J}, \mathrm{~m} / \mathrm{yr}$ & 1.7 & 2.7 & 2.3 & 2.4 \\
\hline$\mu_{I-T}, \mathrm{kPa}$ & 0 & 0 & -0.3 & 0.1 \\
\hline$\sigma_{I-T}, \mathrm{kPa}$ & 0.7 & 6 & 1.7 & 3 \\
\hline$\rho$ & 0.99 & 0.64 & 0.95 & 0.84 \\
\hline \multicolumn{5}{|c|}{ Vector Plastic Model, $\tau_{b, x}, \tau_{b, y}$} \\
\hline$\sqrt{J}, \mathrm{~m} / \mathrm{yr}$ & 3.4 & 4.8 & 4.4 & 5.8 \\
\hline$\mu_{I-T}, \mathrm{kPa}$ & 0.1 & 0.2 & -0.1 & 0.2 \\
\hline$\sigma_{I-T}, \mathrm{kPa}$ & 0.9 & 7.2 & 2 & 3.4 \\
\hline$\rho$ & 0.99 & 0.57 & 0.94 & 0.8 \\
\hline
\end{tabular}

"The mean difference between the "inversion" (I) and "truth" (T) is denoted as $\mu_{I-T}$ and the corresponding standard deviation is denoted by $\sigma_{I-T}$. The correlation coefficient between inversion and truth is denoted by $\rho$. Note that these statistics are calculated only over the areas where the velocity is greater than $300 \mathrm{~m} / \mathrm{yr}$, which covers most of the ice stream bed. The cost function, $J$, is evaluated over the entire model domain.

degree, locally balances the driving stress, so it has a somewhat similar pattern of spatial variability. As a result, the " $50 \%$ of $\tau_{d}$ " appears to provide a robust initial condition that we use in all subsequent inversions.

\subsection{Sensitivity to Velocity Noise}

[26] In this subsection we examine the effect that velocity error has on the quality of the inversions. We created a noisy velocity data set by adding two types of noise to the forward model output. The first type was random-Gaussian noise that had been smoothed to approximately $2-\mathrm{km}$ resolution, which is consistent with the typical resolution of speckletracked InSAR data. The amplitude of the noise for each velocity component was $5 \mathrm{~m} / \mathrm{yr}$ after smoothing. The second type was noise that had been smoothed with a moving average filter by $10 \mathrm{~km}$ in one direction and $150 \mathrm{~km}$ in the other to simulate the ionospheric "streaks" that are often encountered in speckle-tracked InSAR data [Gray et al., 2000]. The amplitudes for this type of noise were 2.5 and $4.3 \mathrm{~m} / \mathrm{yr}$ for the $u$ and $v$ components, respectively. When combined the two types of noise yield uncertainties of $5.6 \mathrm{~m} / \mathrm{yr}$ in the $u$ component and $6.7 \mathrm{~m} / \mathrm{yr}$ in the $v$ component, which is larger the than the typical level of error for WAIS velocities [Joughin et al., 2002]. The error in the magnitude of the velocity is shown in Figure 4.

[27] We performed inversions with all 3 bed models using the synthetic noise data and the " $50 \%$ of $\tau_{d}$ " initial condition. Figure $4 \mathrm{~b}$ illustrates that the errors can be significant on the slow-moving parts outside the ice stream, where the velocity is less than the noise so that the direction is not well constrained. The results are significantly better on the fast moving ice stream, which is the prime area of interest. For the viscous case, the correlation coefficent, $\rho$, dropped slightly $(0.91)$ relative to the noise-free case
(Table 1), and there was no change for the two plastic bed cases, indicating that noise had little effect. Likewise, there was little or no change in $\mu_{I-T}$ (change $\leq 0.1 \mathrm{kPa}$ ) and $\sigma_{I-T}$ (change $\leq 0.3 \mathrm{kPa}$ ) relative to the noise-free experiment, suggesting that the inversion is relatively robust with respect to typical InSAR velocity errors. This is in contrast to unconstrained force balance techniques, which are extremely sensitive to noise since they rely on a double differentiation of the velocity data [Van der Veen, 1999].

\subsection{Sensitivity of Errors in Basal Topography}

[28] We conducted several inversions with noise added to the basal topography. In all cases, we used the noisy velocity data. We performed inversions with bed noise standard deviations, $\sigma_{z_{b}}$, of $10,20,50$ and $100 \mathrm{~m}$. For each noise level, we used a simple moving-average filter to achieve noise with three different length scales (5, 10, $25 \mathrm{~km}$ ), for a total of 12 experiments (4 levels $\times 3$ length scales). Figure 5 shows two examples of the noisy bed topography used in the inversions.

[29] The addition of bed elevation noise had relatively little effect on $\sqrt{J}$, with a worst-case increase in the model-data misfit of less than $1 \mathrm{~m} / \mathrm{yr}$. The quality of the inversion decreased somewhat, with the results tending to worsen with increasing length scale. In all cases, however, the degradation was fairly minimal. The worst-case inversion was with $\sigma_{z_{b}}=100$ and $25-\mathrm{km}$ length scale (see Figure $5 \mathrm{~b}$ ). In this case, the mean difference between the inversion and "truth", $\mu_{I-T}$, ranged from -0.9 to $-1.4 \mathrm{kPa}$, which represents about a $0.7 \mathrm{kPa}$ change from the noise-free case. The corresponding average basal shear stress, $\mu_{\tau_{b}}$, is $8.6 \mathrm{kPa}$. Thus, even in the worst case, the mean error, $\mu_{I-T}$, was only about $16 \%$ of $\mu_{\tau_{b}}$. There were also only small increases in the standard

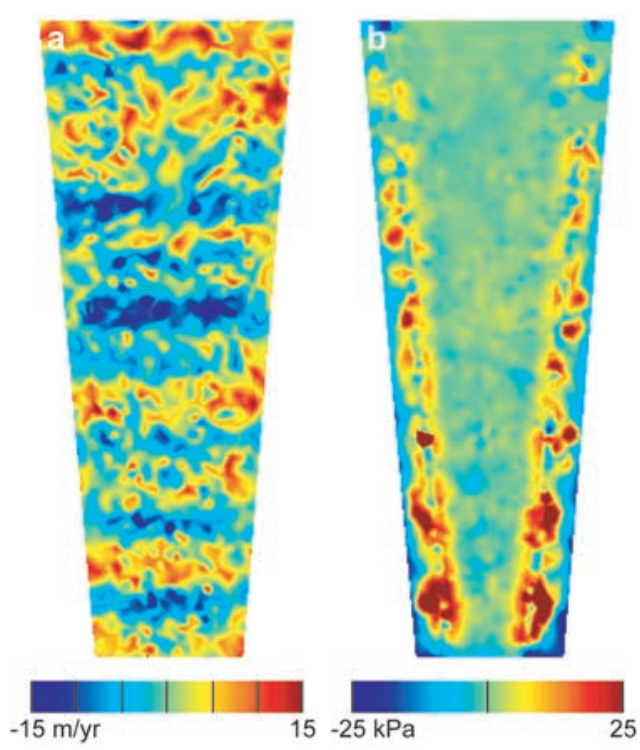

Figure 4. (a) Synthetic velocity noise used in inversions and (b) the corresponding basal shear stress error for the plastic bed inversion. The horizontally banded pattern in the velocity noise is caused by the synthetic "streak" errors. 


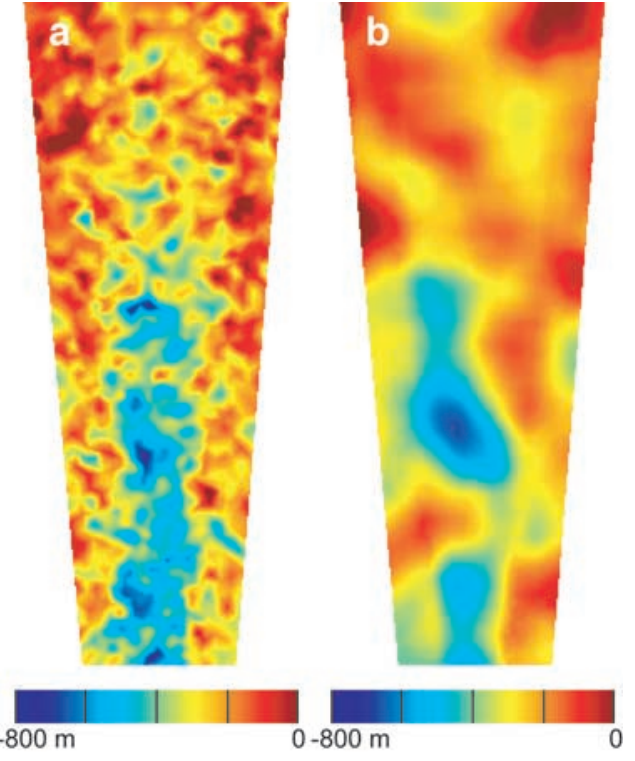

Figure 5. Examples of noisy bed topography with $\sigma_{z_{b}}=$ $100 \mathrm{~m}$ and length scales of (a) $5 \mathrm{~km}$ and (b) $25 \mathrm{~km}$.

deviation of the difference between the inversion and "truth", $\sigma_{I-T}$, with a worst-case value of $2.4 \mathrm{kPa}$. As in the other experiments, both plastic bed inversions yielded slightly better results than the viscous bed model.

[30] We also conducted experiments to examine sensitivity to the horizontal resolution of the bed topography. To simulated degraded resolution, we smoothed the bed elevation with moving average filters with widths of 5, 10, 25, and $50 \mathrm{~km}$. With the 5 - and 10-km smoothing there was little change from the unsmoothed results and, for the $25-\mathrm{km}$ case, the results were comparable to the $25-\mathrm{km}$-scale $100-\mathrm{m}$ noise. For the $50-\mathrm{km}$ case where the smoothing almost completely eliminates any trace of the channel visible in Figure $2, \mu_{I-T}$ increased to $-2.0 \mathrm{kPa}$ and $\sigma_{I-T}$ to $2.5 \mathrm{kPa}$ for the viscous case. The corresponding numbers for the plastic inversions were about $0.5 \mathrm{kPa}$ better.

\subsection{Sensitivity to Errors in Surface Topography}

[31] Driving stress is largely determined by surface slope. Since $\tau_{b}$ in part balances $\tau_{d}$, results are strongly affected by the quality of the surface elevation data used in the inversion. To examine the impact of such noise, we conducted experiments with elevation noise, $\sigma_{z}$, of $5,10,25$, and $50 \mathrm{~m}$ and length scales of $5,10,25$, and $50 \mathrm{~km}$.

[32] Figure 6 shows the effect of noise with $\sigma_{z_{s}}$ and a chacteristic length scale of $10 \mathrm{~km}$. The results in Figures $6 b-6 d$ indicate that the quality of the inversion declines steadily with increasing $\sigma_{z_{s}}$. At $\sigma_{z_{s}}=10 \mathrm{~m}, \sigma_{I-T}$ is nearly a factor of 3 larger than for the noise-free case. Similarly, even the modest noise level of $\sigma_{z_{s}}=5 \mathrm{~m}$ causes nearly a doubling of $\sigma_{I-T}$ in most of the cases we examined. While the results in Figure 6 apply to $10-\mathrm{km}$-scale noise, Figure 7 illustrates that there is a tendency for inversion errors to decline with increasing length scale and its consequent reduction in slope error.

[33] It is interesting to examine the cost function behavior illustrated in Figure 6a. In all of the previous experiments with no elevation noise, the quality of the fit as indicated by $\sqrt{J}$ was consistently poorer for the viscous case. Once surface elevation noise is added, however, the plastic bed inversion tends to yield the larger values of $\sqrt{J}$ than for either the viscous or vector plastic case. Despite these large differences in the model-data misfit, the ability of the three models to determine $\tau_{b}$ does not differ significantly as
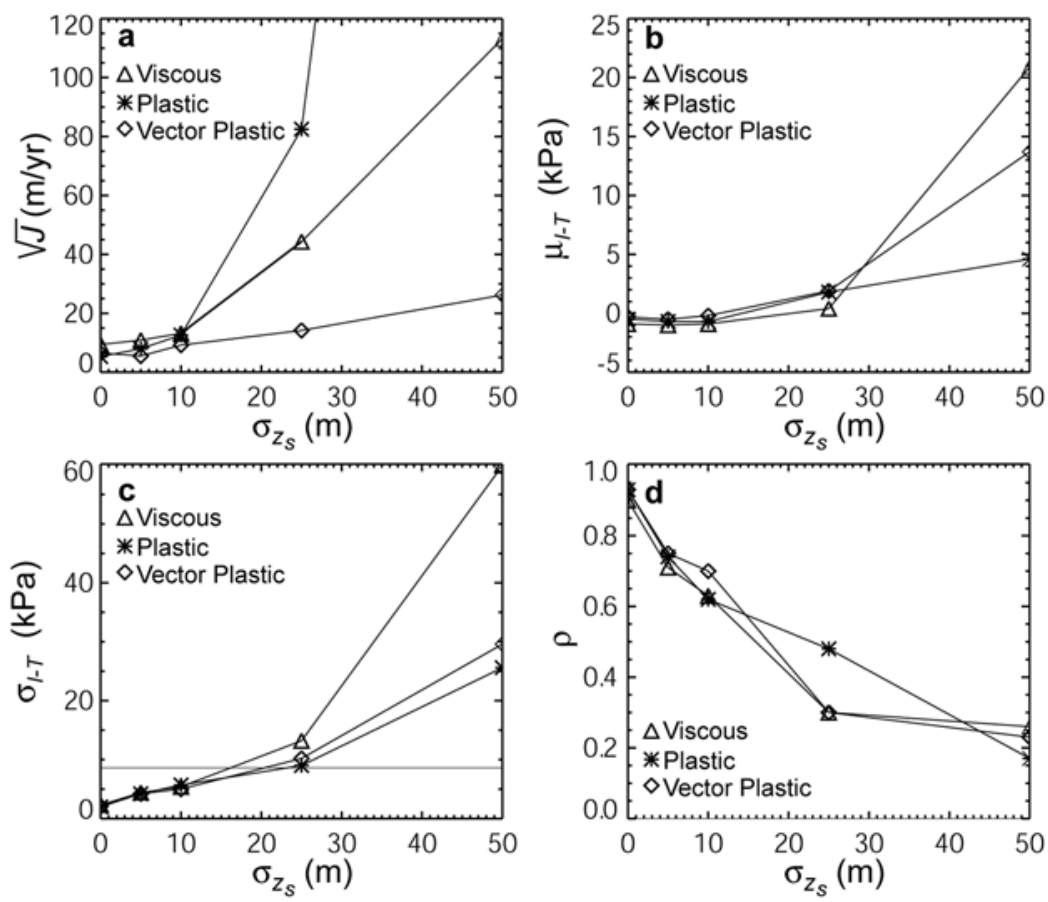

Figure 6. Inversions results for 10-km-scale elevation noise as a function of noise amplitude, $\sigma_{z_{s}}$. Plots show (a) velocity misfit, $\sqrt{J}$, (b) $\mu_{I-T}$, (c) $\sigma_{I-T}$, and (d) $\rho$. 

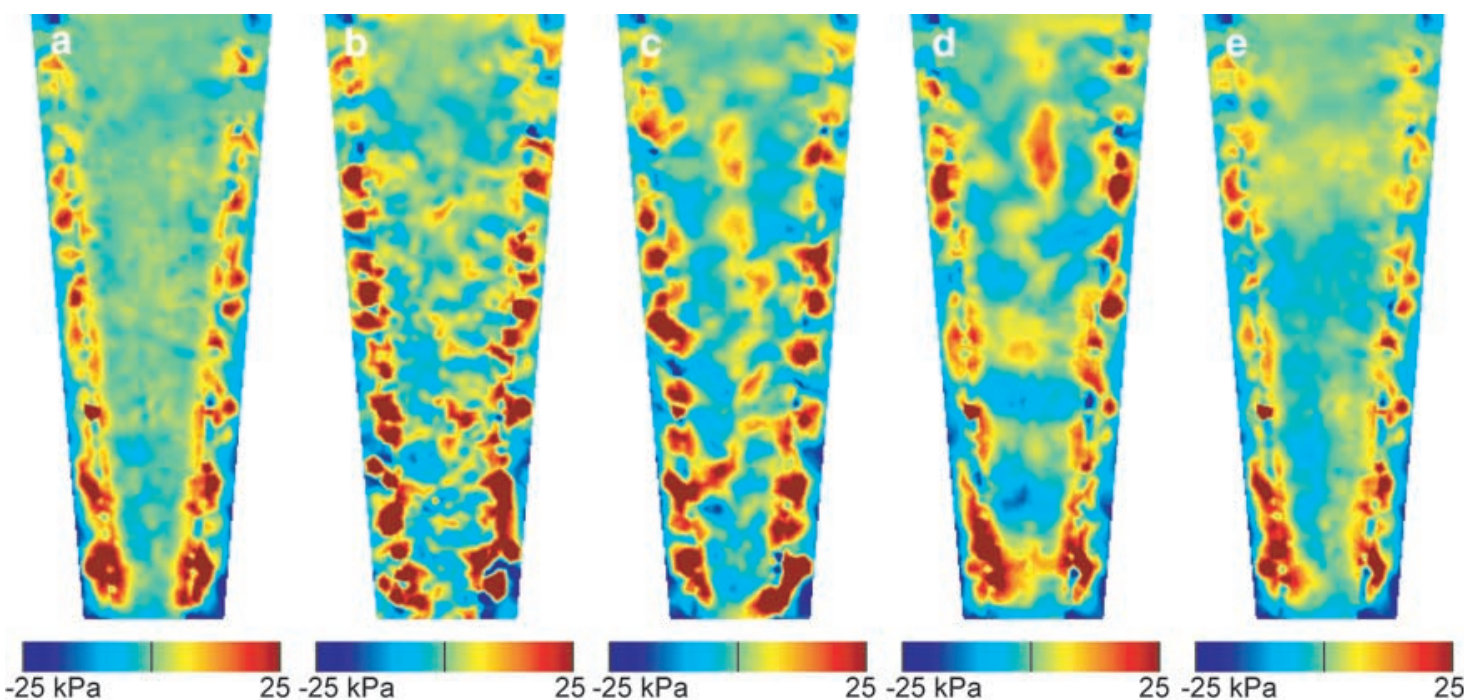

$25-25 \mathrm{kPa}$

$25-25 \mathrm{kPa}$

$25-25 \mathrm{kPa}$

$25-25 \mathrm{kPa}$

Figure 7. Examples of errors in plastic bed basal shear stress inversions with (a) no elevation noise $\left(\mu_{I-T}=-0.5, \sigma_{I-T}=2 \mathrm{kPa}\right)$ and with $\sigma_{z_{\mathrm{s}}}=10 \mathrm{~m}$ and lengths scales of (b) $5 \mathrm{~km}\left(\mu_{I-T}=-0.4, \sigma_{I-T}=\right.$ $6 \mathrm{kPa}),(\mathrm{c}) 10 \mathrm{~km}\left(\mu_{I-T}=-0.7, \sigma_{I-T}=5.7 \mathrm{kPa}\right),(\mathrm{d}) 25 \mathrm{~km}\left(\mu_{I-T}=-0.5, \sigma_{I-T}=5.4 \mathrm{kPa}\right)$, and (e) $50 \mathrm{~km}$ $\left(\mu_{I-T}=-0.8, \sigma_{I-T}=3.2 \mathrm{kPa}\right)$. In all examples, $\sigma_{z_{b}}=50$ with a $10-\mathrm{km}$ length scale.

indicated in Figures $6 \mathrm{~b}-6 \mathrm{~d}$. Thus the quality of the fit as given by $\sqrt{J}$ does not necessarily provide a good means for determining which bed model provides the best inversion.

[34] The ability of the inversion to minimize the modeldata mismatch largely depends on the number of degrees of freedom associated with each node in the finite-element mesh. For the plastic case, there is only one degree of freedom, $\alpha$, at each node. In contrast, for the vector case there are two degrees of freedom, $\tau_{b, x}$ and $\tau_{b, y}$. So for example, if there is a signicant elevation-induced cross-flow error in the $\tau_{d}$, the vector plastic solution can compensate by providing opposing resistance and still maintain a good fit to the velocity data. In contrast, the scalar plastic bed solution can provide resistance only in the along-flow direction, allowing larger model-data mismatch. The viscous model can be thought of as having roughly "one-anda-half" degrees of freedom, because it can alter flow direction to provide additional resistance as needed, provided it improves the overall fit.

\subsection{Sticky Spots}

[35] Longstanding sticky spots should have a corresponding surface expression because additional driving stress is needed to overcome the increased basal resistance [Gudmundsson et al., 1998]. If there has been insufficient time for the surface topography to respond, recently devel-
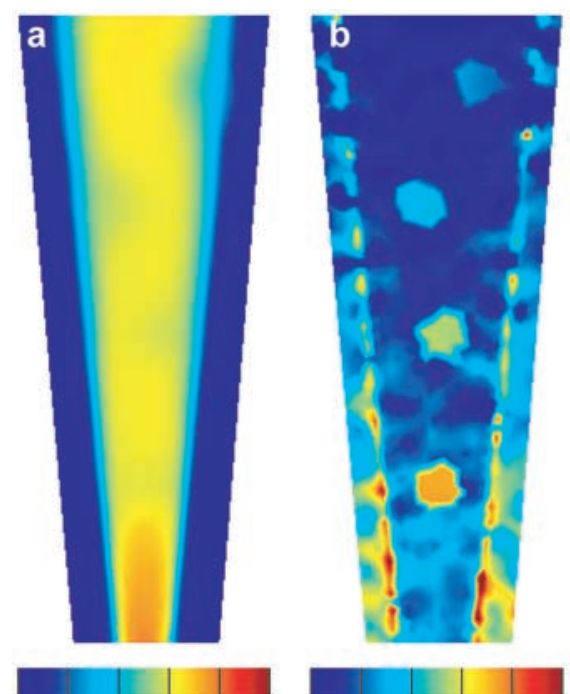

$0 \mathrm{~m} / \mathrm{yr}$

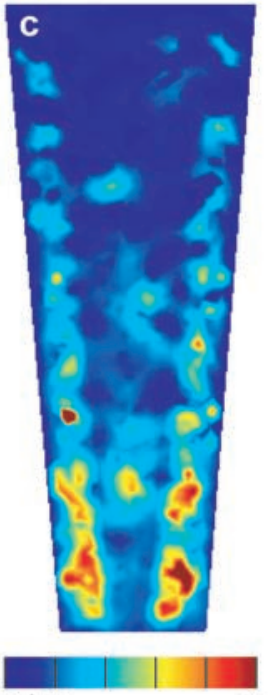

$25-25 \mathrm{kPa}$

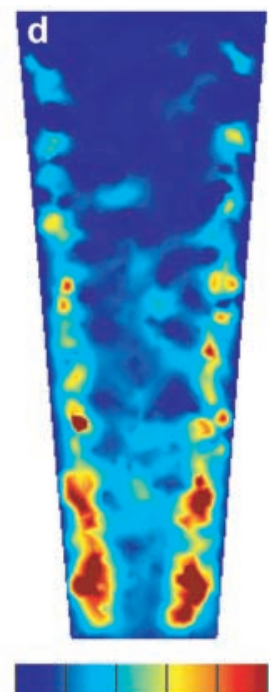

$25-25 \mathrm{kPa}$

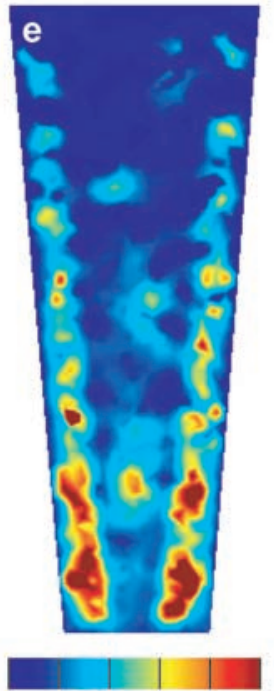

$25-25 \mathrm{kPa}$

Figure 8. Sticky spot experiment results. (a) Velocity with sticky spots, (b) forward model basal shear stress with sticky spots, (c) viscous inversion $\left(\mu_{I-T}=-0.6, \sigma_{I-T}=4 \mathrm{kPa}\right)$, (d) plastic inversion $\left(\mu_{I-T}=\right.$ $\left.0.1, \sigma_{I-T}=4.5 \mathrm{kPa}\right)$, and (e) plastic bed inversion initialized with viscous result $\left(\mu_{I-T}=-0.4, \sigma_{I-T}=\right.$ $4 \mathrm{kPa})$. 
oped sticky spots might have no such topographic signature. Such sticky spots might occur due to basal freeze-on or an increase in effective pressure. The initial condition experiments suggest that the inversion should do reasonably well at detecting sticky spots where there is a surface expression, but may be more limited in cases where there is not. We have performed several experiments with synthetic data to test the ability of the inversion to resolve sticky spots with no surface expression.

[36] Figure 8 shows $\tau_{b}$ and velocity from the forward model with four sticky spots. The viscous inversion (Figure 8c) was able to detect sticky spots at the correct locations, but the recovered sticky spots were much more diffuse in nature than the true spots. The spots recovered by the plastic model were even less distinct. This and other experiments (not shown) suggest that the viscous bed inversion is more capable of detecting sticky spots with no surface expression. This appears to be related to the convergence properties of the viscous bed model rather than the ability of either model to represent sticky spots. When we initialize the plastic model with the final viscous solution, we get nearly identical sticky spots from both models (Figure 8e).

\subsection{Weak Margins}

[37] If the bed is weak, lateral resistance from the margins can provide much of the resistance to the driving stress [Whillans and van der Veen, 1997]. The degree to which the margins provide resistance depends on the ice rheology through $\mathrm{B}$, or equivalently through multiplication of $B$ by some enhancement factor $\left(E^{-1 / 3}\right)$. Thus the use of the incorrect value of the $B$ in the inversion will yield an incorrect partioning between basal and lateral resistance.

[38] To examine the impact of the flow law, we created a new synthetic data set by increasing the basal resistance and using an enhancement factor of $E=10$. The basal resistance was increased such that the resulting velocity was nearly identical to that shown in Figure 2. The synthetic data were then inverted using the original value of $B$. These inversions underestimated the mean basal shear stress by about $4 \mathrm{kPa}$. In general, the bias was smaller toward the downstream end of the stream, where the margins become less signficant as the ice stream widens.

\subsection{Summary of Inversion Experiments}

[39] Our experiments with the synthetic data reveal several aspects of the inversions that need to be taken into account when interpreting inversion results using real data. First, the inversion is not very sensitive to variation in $\tau_{b}$ at the scale of a few ice thicknesses, particularly when the flucuations are relatively weak. Using an initial condition for $\tau_{b}$ that is based on the structure of the driving stress seems to provide the closest fit, but this initial condition can still yield difficulties, particularly if there are sticky spots with no surface expression.

[40] The inversions are fairly robust with respect to the typical level of errors encountered with surface velocity and bed topography data. Surface elevation error, however, can rapidly degrade the quality of the inversion results. Even $5 \mathrm{~m}$ of elevation noise results in significant degradation. Poor knowledge of the flow law parameters can also lead to large uncertainty in the inversions. Furthermore, unlike many of the other sources of error, which largely affect the variability of the estimate, uncertainty in the flow law can introduce large biases in the estimates of mean basal shear stress.

[41] The experiments reveal that for a given model, reduction in peformance measure, $J$, generally yields an improved basal shear stress estimate. The performance measure, however, does not necessarily provide a good indication as to which model yields the best fit, mainly because of differences among the models in the number of degrees of freedom. For example, with signficant amounts of surface elevation error the model-data misfit was smaller for the viscous bed case even though the plastic bed inversion yielded equivalent or better performance. The vector plastic model consistently yielded the lowest values of $J$ but without signficant improvement over either the viscous or plastic model. As a result, for the ice stream inversions described below, we only examine results from the viscous and plastic bed models.

\section{Flow Law Parameterization and Weak Margins}

[42] The outcome of our inversions depends signficantly on the flow law parameters used. In all experiments we make the common assumption that the flow law exponent, $n$, equals 3 [Paterson, 1994]. The flow parameter, $B$, is strongly sensitive to temperature, $T$. As result, we have used a three-dimensional model of heat transfer to determine $B$. This model relied on the velocities shown in Figure 1 to solve for temperature with both horizontal and vertical advection [Joughin et al., 2004]. This model agrees well (e.g., within $\sim 3^{\circ} \mathrm{C}$ ) with borehole measurements and provides a better fit at these locations than do models that include only vertical advection [Paterson, 1994]. Using the three-dimensional model, we compute the temperaturedependent values of $B$ [Paterson, 1994] as function of depth, which are then used to obtain depth-averaged estimates of $B$.

[43] It is often assumed that ice stream margins are signficantly weakened (e.g., $E>1$ ) through strain softening and/or viscous heating [Echelmeyer et al., 1994]. The main basis for this assumption is velocity data from a profile across the margin near the "UpB" camp on Ice Stream B. These data are shown in Figure 9a, which is based on the original figure by Echelmeyer et al. [1994]. Ignoring longitudinal stress gradients, flow speed from the edge to the middle of the ice stream of width, $W$, with uniform thickness and a uniform plastic $\tau_{b}$ can be modeled as [Raymond, 1996]

$$
U=\frac{E A H}{2}\left(\tau_{d}-\tau_{b}\right)^{3}\left(\frac{W}{2 H}\right)^{4}\left[1-\left(1-\frac{2 y}{W}\right)^{4}\right]
$$

where the transverse coordinate, $y$, is equal to 0 at the left edge of the ice stream and W/2 at the ice stream center. This equation can be reflected to yield a symmetrical ice stream profile. A profile of this shape scaled to match the UpB speed is plotted in Figure 9a. Echelmeyer et al. [1994] argued that the sharper margin of the measured profile with respect to the theoretical profile is the result of significant 

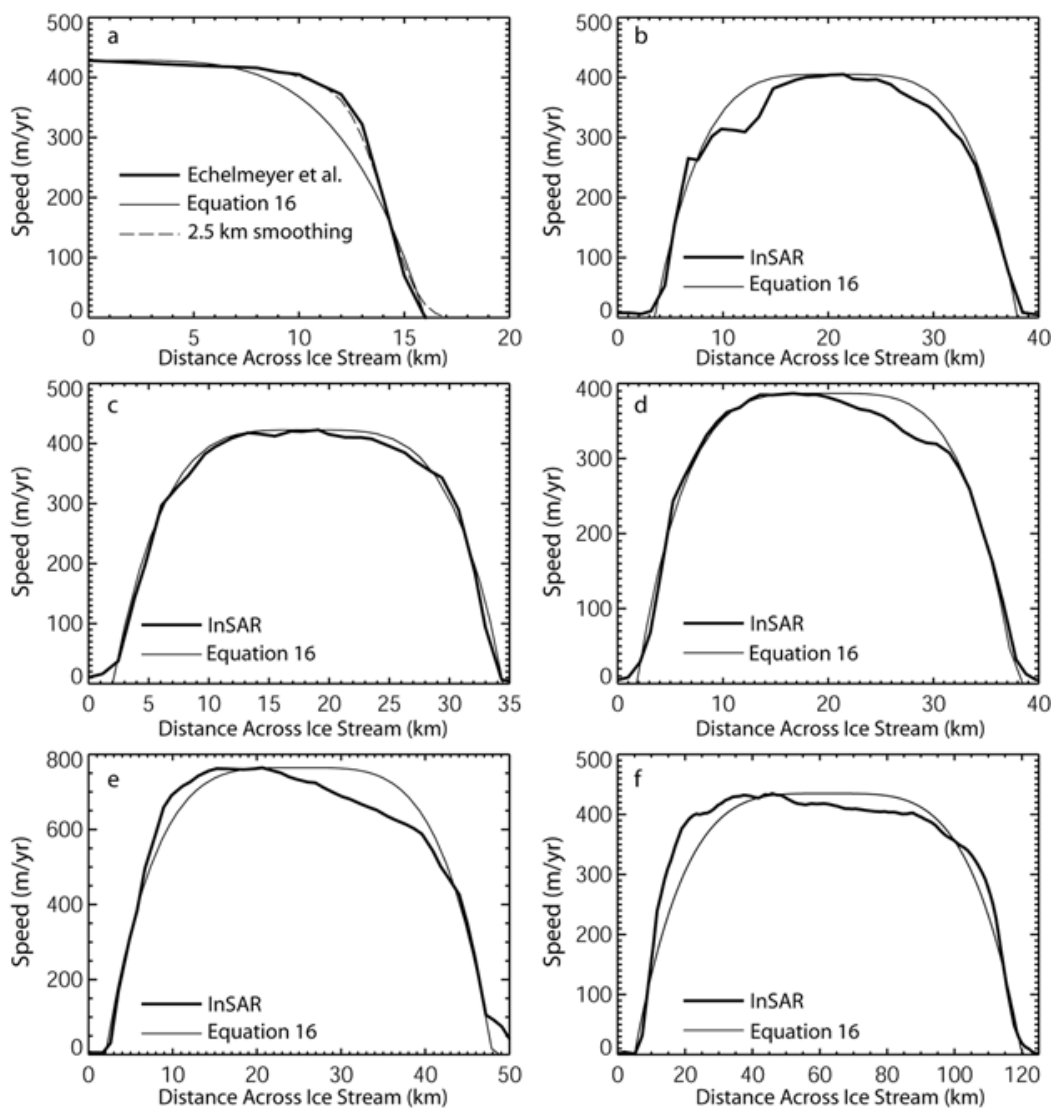

Figure 9. (a-f) Ice stream flow speed profiles and corresponding best fit $W^{4}$ dependence. Data digitized from Echelmeyer et al. [1994] (Figure 9a). Dashed lines show the effect of smoothing on profile shape. Locations of profiles in Figures $9 b-9 f$ are shown with orange lines in Figure 1.

softening of the margin $(E=10)$ across the roughly $2.5-\mathrm{km}$ wide margin. This observation has formed one of the main arguements for margin softening.

[44] Other results support little or no margin softening. Laboratory tests of ice samples extracted from the margin suggest little or no margin enhancement [Jackson and Kamb, 1997]. It has also been suggested that cooling of the upper ice column through the high density of open crevasses at the margin may act to strengthen the margins, perhaps offsetting any enhancement [Harrison et al., 1998]. It has also been argued that a single profile forms the basis for margin softening and that this analysis ignores shortscale fluctuations in thickness and $\tau_{d}$ [Van der Veen, 1999]. To explore this argument further we examined several additional ice stream profiles.

[45] The plots in Figures 9b-9f show profile comparisons of measured and theoretical flow speed at several locations on Ice Stream B. Measured flow speeds across several margins agree well with their theoretical counterparts, suggesting little or no margin softening. This agreement is especially good considering that there is no accounting for lateral variation in any of the parameters. The differences for two margins (left margins, Figures 9e and 9f) resemble the difference in Figure 9a used to argue for margin softening. There are three margins (Figures $9 \mathrm{~b}$ and $9 \mathrm{~d}$ ), however, where the opposite is true and theoretical profiles rise more steeply at the margins than do the measured data. We note that the InSAR data shown in Figures 9b-9f have poorer resolution $(\sim 2.5-\mathrm{km})$ than the Echelmeyer et al. [1994] survey data $(\sim 0.5 \mathrm{~km})$. To evaluate this effect, we have smoothed the survey data in Figure 9a with a moving average filter of width of $2.5 \mathrm{~km}$. The change in the shape of the profile is not large enough to suggest that the lower resolution of the InSAR data is greatly affecting the profiles shapes.

[46] Along with other observations [Harrison et al., 1998; Jackson and Kamb, 1997], these profiles suggest that departures from the theoretical profiles are not the result of margin softening, which should affect all profiles, but rather are the result of lateral fluctuations in the ice stream parameters not accounted for by equation (16) [Van der Veen, 1999]. This does not rule out a uniform softening of the ice across the ice stream since a spatially invariant enhancement parameter, $E$, affects the magnitude but not the shape of the profile given by equation (16).

\section{Data}

[47] To address the real WAIS, we used a map (Figure 1) derived from InSAR, LandSAT feature tracking, and GPS survey [Joughin et al., 2002] to constrain the inversions. Error estimates for most of the data set are below $5 \mathrm{~m} / \mathrm{yr}$, and these estimates agree well with results from GPS/ Doppler surveys.

[48] Figure 10 shows the BEDMAP bed topography used in the inversions [Lythe and Vaughan, 2001]. These data are 


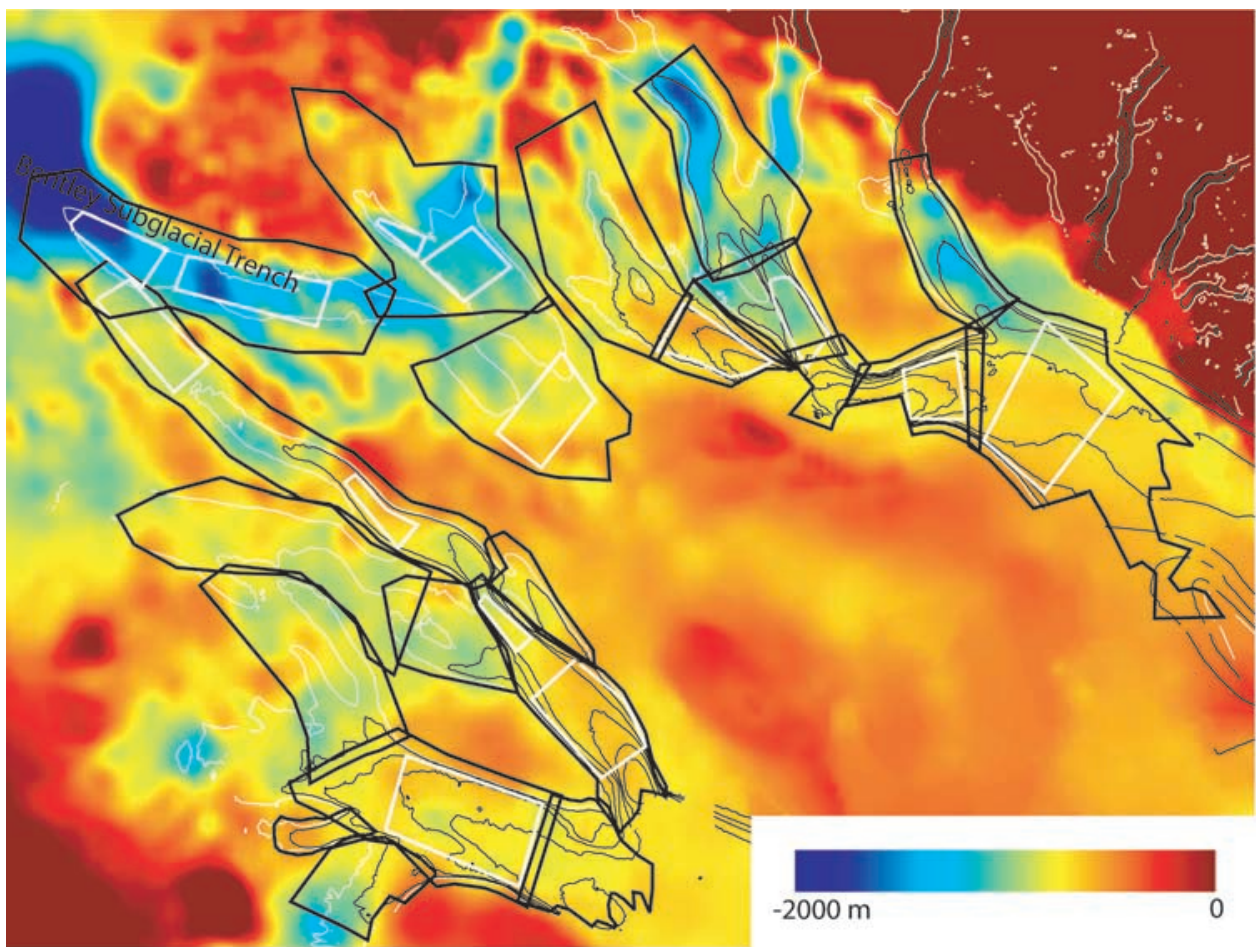

Figure 10. Bed topography from the BEDMAP data set [Lythe and Vaughan, 2001]. Thick black lines show regions were inversions were performed, and thick white lines show boxes over which results were averaged. Flow speed is contoured at $50 \mathrm{~m} / \mathrm{yr}$ (thin white line) and at $100 \mathrm{~m} / \mathrm{yr}$ intervals (thin black lines).

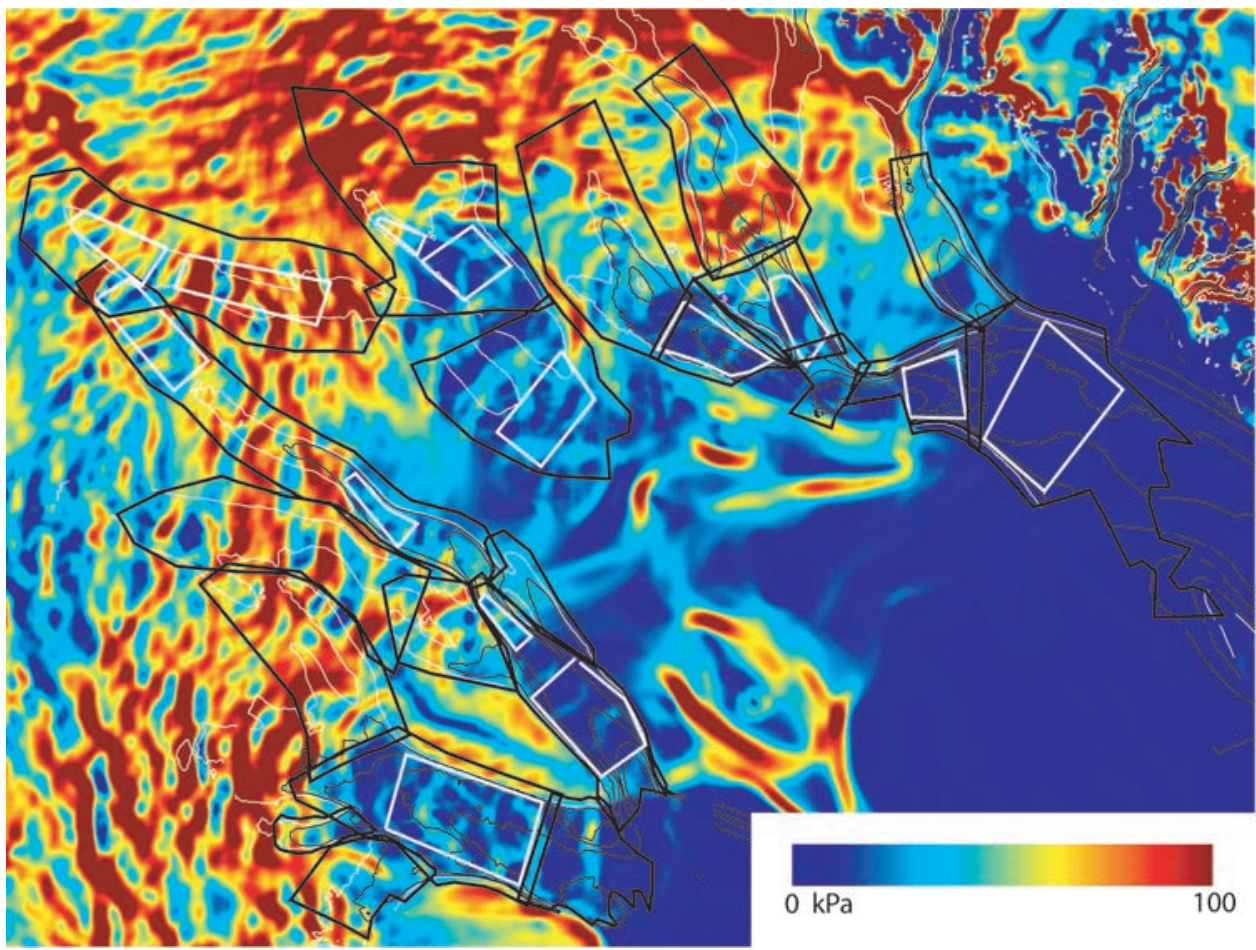

Figure 11. Driving stress for the Siple Coast Ice Streams. Thick black lines show regions were inversions were performed, and thick white lines show boxes over which results were averaged. Flow speed is contoured at $50 \mathrm{~m} / \mathrm{yr}$ (thin white line) and at $100 \mathrm{~m} / \mathrm{yr}$ intervals (thin black lines). 


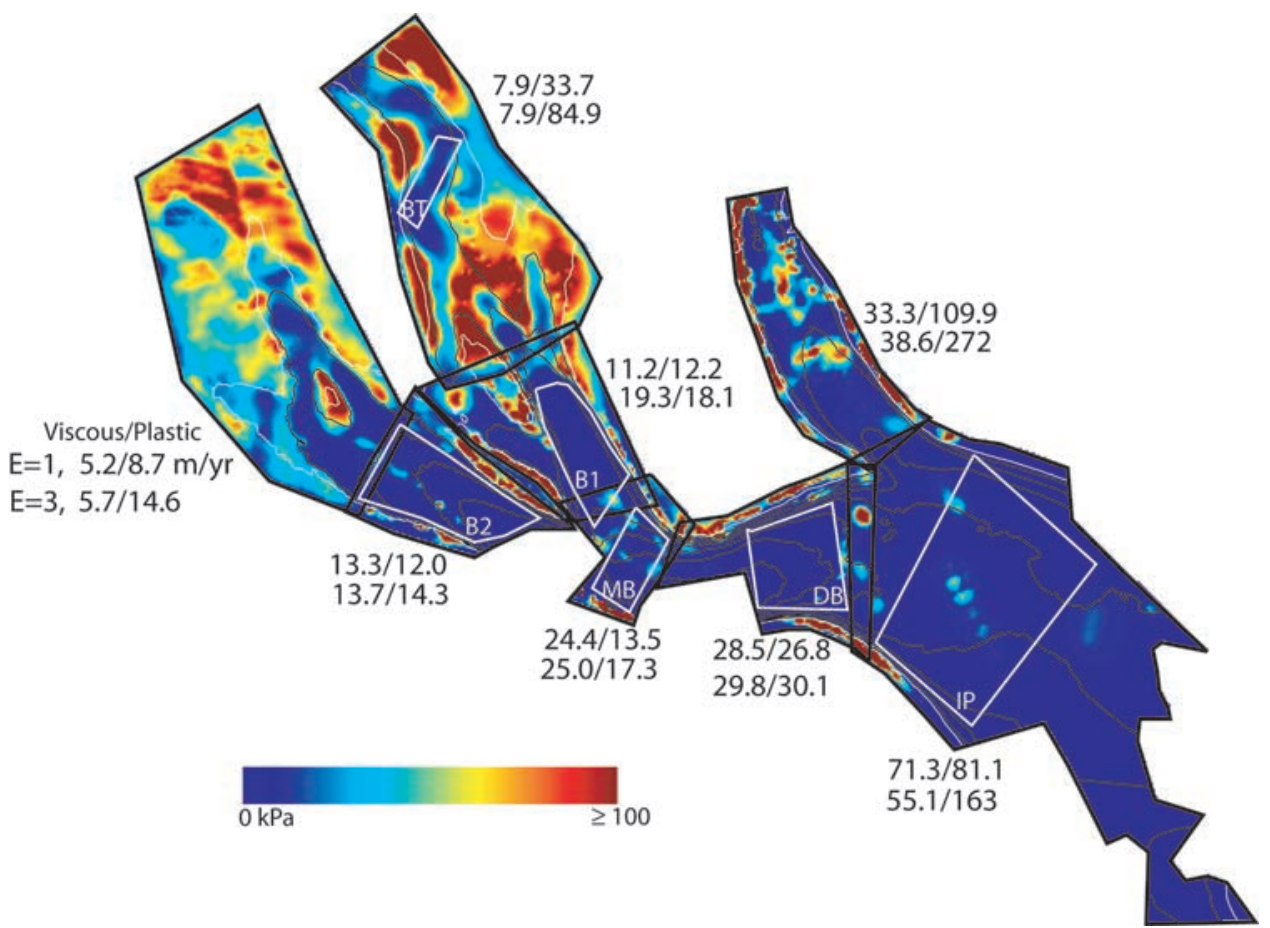

Figure 12. Basal shear stress from the plastic bed inversion for Ice Streams A and B. Thick black lines outline the regions over which individual inversions were performed. Thick white lines refer to sampling boxes discussed in the text and in Table 1 . Flow speed is contoured at $50 \mathrm{~m} / \mathrm{yr}$ (thin white line) and at $100 \mathrm{~m} / \mathrm{yr}$ intervals (thin black lines). The numbers beside each region give the values of the performance measure, $\sqrt{J}$, for both bed models (viscous/plastic). These values are also included for flow with no enhancement ( $E=1$, top) and with enhancement of $E=3$ (bottom).

posted at $5-\mathrm{km}$ intervals, although actual resolution depends on the density of the source data. Fortunately, extensive radio echo mapping efforts [Blankenship et al., 2001; Retzlaff et al., 1993] have made the area shown in Figure 10 one of the better mapped regions in Antarctica. Much of the area that includes Ice Streams B, C, and $\mathrm{D}$ has been flown with grids with $5-$ to $10-\mathrm{km}$ spacing. For Ice Streams $A$ and $E$, the resolution is considerably poorer with some flightlines spaced up to $50 \mathrm{~km}$ apart.

[49] For surface topography we relied largely on the RADARSAT Antarctic Mapping Mission Digital Elevation Model (DEM) [Liu et al., 1999]. We improved this DEM in some areas through the addition of more recent data sets [Blankenship et al., 2001]. We smoothed the DEM to a resolution of $11 \mathrm{~km}$ to help reduce errors in evaluating slope and driving stress. Figure 11 shows $\tau_{d}$ as determined from the surface and bed elevation data sets. The quality of the surface elevation data is quite variable, depending on what source data were available for each region. Much of Ice Streams D and E (north of $81.5^{\circ} \mathrm{S}$ ) is covered by the ERS- $1 / 2$ altimeters, so the topography is reasonably well known at the $11-\mathrm{km}$ scale to which we smoothed the DEM. The topopgraphy is also well known for much of the upstream areas of Ice Streams B and C, where airborne altimeters have collected data. In contrast, much of Ice Stream A and the ice plains of Ice Streams B and C have only been sparsely sampled (e.g., $50 \mathrm{~km}$ ), and the topography of these regions is poorly known.

\section{Ross Ice Stream Inversions}

[50] As part of the inversion process, each ice stream (AE) was broken up into several regions (see Figure 10) that were inverted individually to speed convergence. Application of the inversion procedure to smaller areas also yields better results in terms of model-data mismatch. After determing $\tau_{b}$ for each region, we combined the results into maps of $\tau_{b}$ for each ice stream. This process was applied separately to both the viscous and plastic bed models. The remainder of this section describes the results for the individual ice streams.

\subsection{Ice Streams A and B}

[51] Figure 12 shows the plastic bed inversion result for Ice Streams A and B. Both the plastic and viscous bed (not shown) inversions yield similar results. These estimates of $\tau_{b}$ indicate that the weak-bedded regions beneath the ice streams are well correlated with regions of enhanced flow speed and low driving stress (Figure 11). Unlike many of their respective ice streams, tributaries are not always obviously visible as well defined areas of low driving stress (e.g., Figure 11). In some areas there are pockets of low driving stress associated with tributaries, while in other areas no such features are 
Table 2. Values of $\tau_{d}$ and $\tau_{b}$ Averaged Over the Boxes Shown in Figures 12,13 , and $14^{\mathrm{a}}$

\begin{tabular}{|c|c|c|c|c|c|c|c|}
\hline \multirow[b]{3}{*}{ Box } & \multirow{3}{*}{$\begin{array}{l}\tau_{d} \\
\mathrm{kPa}\end{array}$} & \multicolumn{3}{|c|}{$E=1$} & \multicolumn{3}{|c|}{$E=3$} \\
\hline & & \multicolumn{2}{|c|}{$\tau_{b}, \mathrm{kPa}$} & \multirow[b]{2}{*}{$\tau_{b} / \tau_{d}$} & \multicolumn{2}{|c|}{$\tau_{b}, \mathrm{kPa}$} & \multirow[b]{2}{*}{$\tau_{b} / \tau_{d}$} \\
\hline & & Viscous & Plastic & & Viscous & Plastic & \\
\hline \multicolumn{8}{|c|}{ Ice Stream B } \\
\hline BT & 40.7 & 8.4 & 12.6 & $26 \%$ & 17.0 & 24.4 & $51 \%$ \\
\hline B1 & 20.7 & 1.2 & 1.8 & $7 \%$ & 4.3 & 5.8 & $24 \%$ \\
\hline B2 & 15.4 & 2.8 & 2.8 & $18 \%$ & 5.5 & 5.3 & $35 \%$ \\
\hline MB & 20.5 & 6.2 & 6.0 & $30 \%$ & 8.6 & 9.0 & $43 \%$ \\
\hline DB & 7.9 & 0.6 & 0.5 & $7 \%$ & 2.5 & 2.3 & $31 \%$ \\
\hline IP & 5.2 & 1.3 & 1.7 & $29 \%$ & 2.8 & 2.0 & $46 \%$ \\
\hline \multicolumn{8}{|c|}{ Ice Stream C } \\
\hline CT1 & 58.5 & 36.4 & 36.5 & $62 \%$ & 43.0 & 42.9 & $73 \%$ \\
\hline $\mathrm{CT} 2$ & 90.0 & 77.8 & 81.3 & $88 \%$ & 81.0 & 84.5 & $92 \%$ \\
\hline $\mathrm{CO}$ & 44.7 & 9.6 & 11.0 & $23 \%$ & 18.8 & 19.3 & $43 \%$ \\
\hline CA & 18.5 & 8.5 & 8.6 & $46 \%$ & 10.7 & 10.7 & $58 \%$ \\
\hline $\mathrm{CS}$ & 23.1 & 18.8 & 18.0 & $80 \%$ & 19.5 & 18.6 & $82 \%$ \\
\hline \multicolumn{8}{|c|}{ Ice Stream D } \\
\hline DT & 45.3 & 38.8 & 39.4 & $86 \%$ & 40.1 & 42.0 & $91 \%$ \\
\hline DO & 29.7 & 7.7 & 9.2 & $28 \%$ & 13.6 & 13.8 & $46 \%$ \\
\hline UD & 23.2 & 0.8 & 1.2 & $4 \%$ & 6.7 & 7.2 & $30 \%$ \\
\hline DS & 11.8 & 3.9 & 4.2 & $34 \%$ & 5.5 & 5.8 & $48 \%$ \\
\hline \multicolumn{8}{|c|}{ Ice Stream E } \\
\hline ES & 21.4 & 14.8 & 14.9 & $69 \%$ & 16.1 & 15.9 & $75 \%$ \\
\hline
\end{tabular}

${ }^{\mathrm{a}}$ The average of plastic and viscous values was used to compute $\tau_{b} / \tau_{d}$ percentages.

visible. The basal shear stress (Figure 12), however, indicates that the weak-bedded tributary regions are relatively continuous and coincide well with regions of enhanced flow. Comparison with Figure 10 indicates that weak tributary regions are coincident with the bottoms of the sedimentary basins through which they flow [Blankenship et al., 2001; Joughin et al., 1999; Studinger et al., 2001]. Within these basins there appears to be a weak correspondence between the stronger-bedded regions and relative highs in the bed topography and/or narrower regions of the basins.

[52] Figure 12 includes the model-data misfit value, $\sqrt{J}$, for each region. For the upper four regions (Ice Streams B1 and $\mathrm{B} 2$ and their tributaries), analogy with the synthetic data inversions suggests errors in the surface topography of about $5-12 \mathrm{~m}$. These elevation errors are roughly consistent with the expected errors. The synthetic data inversions also indicate that the mean $\tau_{b}$ values for these regions should be reliable to within about $\pm 1 \mathrm{kPa}$, assuming no errors in $E$ or $B$. For the regions contained within the "MB" and "DB" boxes, the $\sqrt{J}$ values suggest slightly higher elevation errors $(\sim 15 \mathrm{~m})$, leading to uncertainty in mean $\tau_{b}$ values of roughly $\pm 1.5 \mathrm{kPa}$. Surface elevations for the regions containing the Ice Plain and Ice Stream A are based on sparse data that have much poorer accuracy. The $\sqrt{J}$ values suggest elevation errors of about $25 \mathrm{~m}$, leading to uncertainty in the mean $\tau_{b}$ estimates of roughly $\pm 2.0 \mathrm{kPa}$. In these latter two cases, we also expect considerable uncertainty in the spatial structure of the inferred basal shear stress distribution.

[53] For the UpB region, which contains the B2 box, we performed additional experiments in which ice in the margins was weakened by applying a value $\mathrm{E}=10$ while maintaining $\mathrm{E}=1$ outside the margins. This had the effect of significantly increasing $\sqrt{J}$ from 13.3 and $12.0 \mathrm{~m} / \mathrm{yr}$ to 17.9 and $40.4 \mathrm{~m} / \mathrm{yr}$ for the viscous and plastic models, respectively. This result supports our above described hypothesis that there is little or no margin-specific weakening of ice.

[54] To further evaluate the sensitivity to uncertainty in the flow law enhancement factor, we performed inversions both with $(E=3)$ and without $(E=1)$ uniform strain rate enhancement. The value of 3 is slightly larger than the value of 2.5 that might be expected for ice with a strong singlemaximum fabric [Paterson, 1994], although enhancement factors as high as 10 have been proposed for the margins [Echelmeyer et al., 1994]. Although in some cases the differences were small, in nearly every case the model was better able to match the data with no enhancement.

[55] Table 2 shows the values for $\tau_{d}$ and $\tau_{b}$ averaged over the boxes shown in Figure 12. Box "BT" includes part of the weak bed for the tributary feeding Ice Stream B1. Over this box the viscous and plastic inversions with no enhancement yield average $\tau_{b}$ values of 8.4 and $12.6 \mathrm{kPa}$, respectively. These values are larger than measurements for till samples recovered beneath ice streams $(\sim 2 \mathrm{kPa})[\mathrm{Kamb}$, 1991], but still are indicative of a weak bed. When strain enhancement $(E=3)$ is considered, the corresponding values of $\tau_{b}$ nearly double since the margins are less able to provide resistance. Considering both values of $E$, the bed supports about 26 to $51 \%$ of $\tau_{d}$ beneath box BT, which is one of the weaker tributary regions. This range agrees well with a prior estimate of $37 \%$ from force balance estimates for approximately the same region [Joughin et al., 2002].

[56] On Ice Streams B1 and B2 (boxes "B1" and "B2") the $\tau_{b}$ estimates range from 1.2 to $2.8 \mathrm{kPa}$ with no enhancement, which is similar to values of $\sim 2 \mathrm{kPa}$ from borehole torvane measurements near the UpB camp [Kamb, 2001]. Despite this agreement for the mean value, the inversions yield zero or near-zero values of $\tau_{b}$ for much of the bed under the "B1" and "B2" boxes. The $\sim 2 \mathrm{kPa}$ average is the result of spots of greater resistance within the boxes. For the B2 box in particular, these more resistive spots coincide well with the locations of crevasses visible in synthetic aperture radar (SAR) imagery. When strain rate enhancement is considered, the bed is roughly $3 \mathrm{kPa}$ stronger $(4.3$ to $5.8 \mathrm{kPa}$ ) for boxes $\mathrm{B} 1$ and $\mathrm{B} 2$. Like the case with no enhancement, much of the bed resistance is provided by regions of greater resistance. This means that even with enhancement, $\tau_{b}$ is still less than $3 \mathrm{kPa}$ for roughly $50 \%$ of the area within boxes B1 and B2, which is still consistent with the observations of weak till at a sparse distribution of boreholes [Kamb, 2001]. Irrespective of whether there is enhancment, the inversions do not provide sufficient resolution to determine whether the regions of increased resistance represent broad areas of till with greater resistance (e.g., $5-10 \mathrm{kPa}$ ) or smaller but strong (e.g., 50-200 kPa) sticky spots.

[57] The driving stress $(20.5 \mathrm{kPa})$ for the mid-B box (MB) is relatively large for an ice stream, and the bed provides greater resistance $(6.2$ to $9.0 \mathrm{kPa})$ than it does for the adjacent upstream and downstream regions. This region is near the edge of one of the airborne grids flown to acquire elevation/thickness data, so these larger bed and surface values may be caused by error in the surface elevation. 


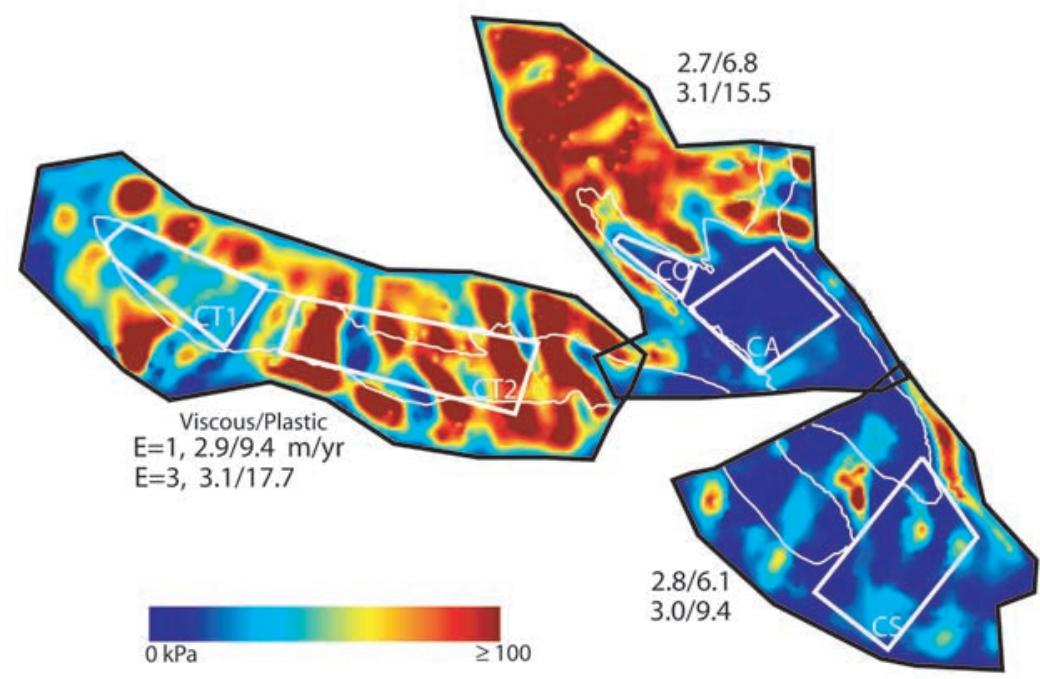

Figure 13. Basal shear stress from the plastic bed inversion for Ice Stream $C$. Thick black lines outline the regions over which individual inversions were performed. Thick white lines refer to sampling boxes discussed in the text and in Table 1. Flow speed is contoured at $50 \mathrm{~m} / \mathrm{yr}$ (thin white line) and at $100 \mathrm{~m} / \mathrm{yr}$ intervals (thin black lines). The numbers beside each region give the values of the performance measure, $\sqrt{J}$, for both bed models (viscous/plastic). These values are also included for flow with no enhancement ( $E=1$, top) and with enhancement of $E=3$ (bottom).

[58] The bed is weak ( 0.5 to $2.5 \mathrm{kPa})$ beneath the box DB. Even with ehancement $\tau_{b}$ is effectively zero over most of the box, with most of the resistance resulting from strong spots near the downstream end of the box. Although the mean values from the inversion are reasonably robust, the poor quality of the elevation data in this region makes it difficult to tell whether these downstream stronger spots are real features or artifacts introduced by the inversion.

[59] The mean $\tau_{b}$ values of 1.3 to $2.8 \mathrm{kPa}$ for the Ice Plain (IP) box are consistent with force balance estimates [Joughin et al., 2002] and with in situ and lab measurements of till from boreholes farther upstream [Kamb, 2001]. The model-data misfit and the poor quality of the elevation data in this region, however, mean that the sticky spots shown in the center of the Ice Plain are likely artifacts that the inversion produces as it compensates for large errors in the surface topography. Likewise, Ice Stream A appears to have a relatively weak bed over its downstream end, but we have little confidence in whether the inferred sticky spots have any basis in reality.

\subsection{Ice Stream $\mathbf{C}$}

[60] Figure 13 shows the plastic inversion results for Ice Stream C and its tributaries. The results indicate a relatively strong bed beneath much of the tributary flowing along the Bentley Subglacial Trench and a weak bed in the active region upstream of the stagnant lower reaches of the ice stream. The reasonably good elevation data $(5-10 \mathrm{~m}$ errors) in this region are reflected by the relatively small $\sqrt{J}$ values. We anticipate that, excluding flow law uncertainties, the uncertainty in mean $\tau_{b}$ estimates for the weak-bedded regions is roughly $\pm 1 \mathrm{kPa}$ or better. We have calculated average $\tau_{b}$ and $\tau_{d}$ values for the five boxes shown in Figure 13, which are tabulated in Table 2.

[61] Box "CT1" is located near the origin of the large tributary flowing through the Bentley Subglacial Trench.
The mean basal shear stress of $36.5 \mathrm{kPa}$ over this box suggests a slight weakening of the bed, with a trend toward a stronger bed in the downstream direction. The weaker areas coincide with the very deep subglacial areas where sediments may have collected. Further downstream in the deep channel, the results for box "CT2" indicate a signficantly stronger bed that resists most $(88-92 \%)$ of the driving stress. With this level of basal resistance, a signficant fraction of the surface velocity is likely attributable to ice deformation [Hulbe et al., 2000], so that the depthaveraged ice stream model is not strictly applicable. This means that caution should be excercised in interpreting the structure visible in the inferred $\tau_{b}$ distribution, such as the alternating pockets of strong and weak bed. Nevertheless, the conclusion of a strong bed in this region is robust.

[62] Box "CO" is located just downstream of an area of relatively diffuse but enhanced flow that coalesces into the relatively narrow region of focussed flow containing the box. This region has been interpreted as being an onset of Ice Stream $C$ that is coincident with a sedimentary basin [Anandakrishnan et al., 1998; Bell et al., 1998]. The average bed strength over this box ranges from 9.6 to $19.3 \mathrm{kPa}$, which corresponds to 23 to $43 \%$ of $\tau_{d}$. This relatively weak bed is consistent with seismic observations that indicate the presence of a layer of weak till beneath this region [Anandakrishnan, 2003].

[63] Figure 13 indicates that most of the still active region beneath Ice Stream $\mathrm{C}$ is relatively weak. A strong sticky spot is located in the center of the ice stream, which is coincident with the velocity minimum at the center of the ice stream. A region of the active area is sampled by Box CA over which the mean $\tau_{b}$ estimates range from 8.5 to $10.7 \mathrm{kPa}$ (Table 2). The relatively low sensitivity to the enhancement factor likely reflects the relatively broad ice stream width in this region and potentially some longitudinal resistance from the stagnant area further downstream. 


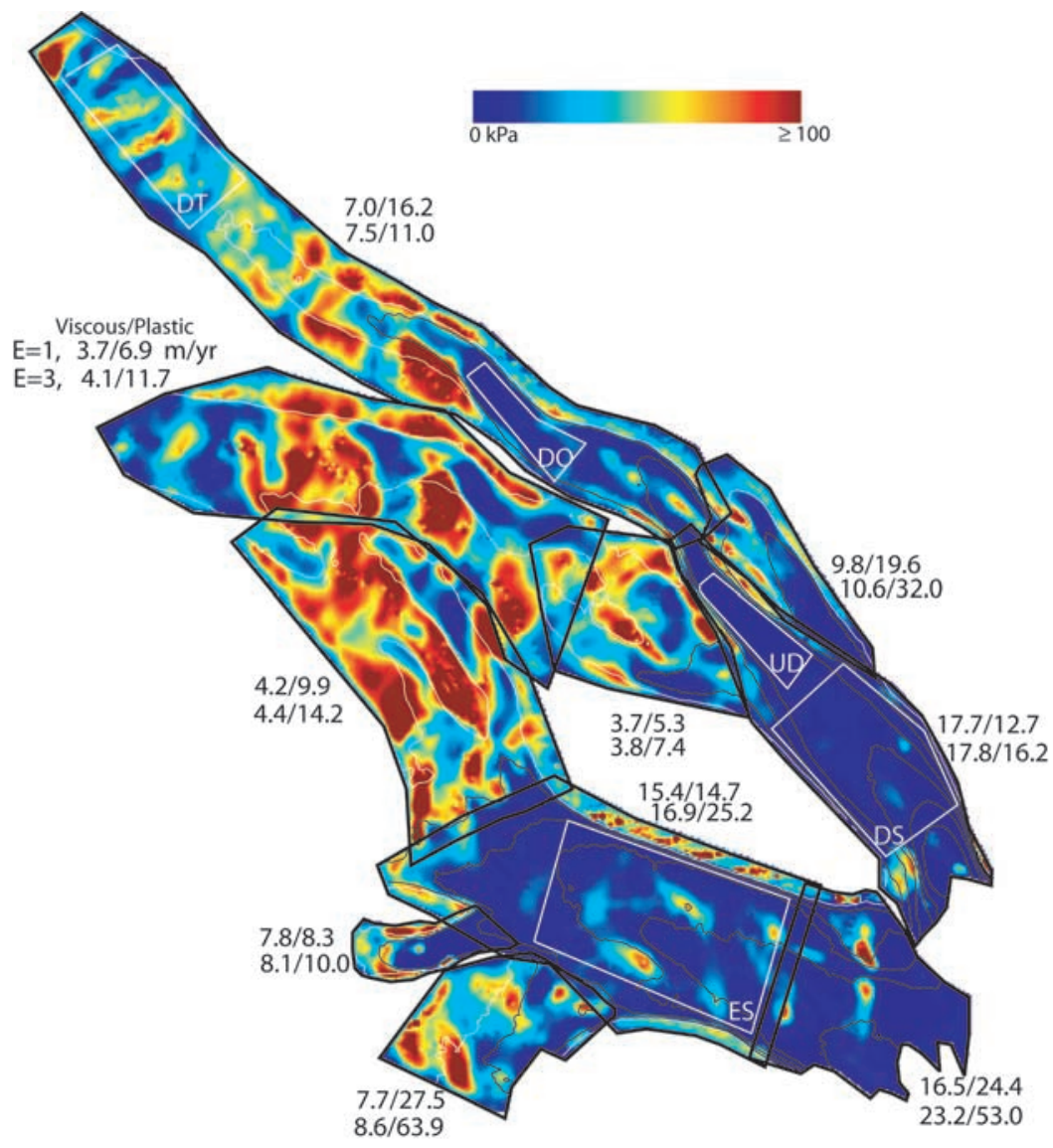

Figure 14. Basal shear stress from the viscous bed inversion for Ice Streams D and E. Thick black lines outline the regions over which individual inversions were performed. Thick white lines refer to sampling boxes discussed in the text and in Table 1. Flow speed is contoured at $50 \mathrm{~m} / \mathrm{yr}$ (thin white line) and at $100 \mathrm{~m} / \mathrm{yr}$ intervals (thin black lines). The numbers beside each region give the values of the performance measure, $\sqrt{J}$, for both bed models (viscous/plastic). These values are also included for flow with no enhancement ( $E=1$, top) and with enhancement of $E=3$ (bottom).

[64] Box "CS" covers much of the transition from active to stagnant flow [Anandakrishnan, 2003; Joughin et al., 1999]. The mean $\tau_{b}$ estimate for this region (18.0 to $19.5 \mathrm{kPa})$ is about twice that in the active region and provides about $80 \%$ of the resistance to $\tau_{d}$. There is a signficant amount of variation in $\tau_{b}$ over this box ranging from near-zero values to sticky spots with peak shear stresses of roughly $80 \mathrm{kPa}$. The weaker areas within the box roughly coincide with regions of deeper bed topography (see Figure 10). This may indicate areas with greater sedimentation or a warmer bed due to the thicker overlying ice. Basal melt models indicate that most of the active area coincides with areas where there is still basal melt whereas the stopped regions overly areas of basal freezing [Joughin et al., 2003, 2004].

\subsection{Ice Stream D}

[65] Figure 14 shows the inferred basal shear stress for Ice Stream D. Nearly all of this ice stream as well as Ice Stream E falls within the coverage of the ERS-1/2 radar altimeters, which provide relatively accurate data on low slopes such as those of the Ross ice streams. Consequently, the $\sqrt{J}$ values are relatively small, and we anticipate uncertainty in area-averaged $\tau_{b}$ values of about $\pm 1 \mathrm{kPa}$.
[66] Ice Stream D is fed by a long tributary that extends inland to a common origin with the tributary that feeds Ice Stream C through the Bentley Subglacial Trench [Joughin et al., 1999]. This tributary flows at about $40-60 \mathrm{~m} / \mathrm{yr}$ for roughly $175 \mathrm{~km}$ over a bed that has a significant degree of variation in $\tau_{b}$. Box "DT" samples a large section of this region and yields a mean basal shear stress of about $40 \mathrm{kPa}$, with little sensitivity to the value of $E$. This value is consistent with force balance results for this region [Joughin et al., 2002; Price et al., 2002]. The distribution of $\tau_{b}$ over this box is considerably less variable than the corresponding driving stress. Price et al. [2002] peformed an extensive force balance in this region using data from a dense GPS survey grid and concluded that longitudinal stress gradients act in such a way as to smooth out much of the variability in the basal resistance to $\tau_{d}$ to facilitate more uniform sliding.

[67] Force balance estimates were used to determine that the "onset" of Ice Stream D approximately coincides with the $100 \mathrm{~m} / \mathrm{yr}$ contour [Price et al., 2002]. Just above the $100 \mathrm{~m} / \mathrm{yr}$ contour, speed increases at the beginning of a roughly $150-\mathrm{km}$ long region of sustained bed weakness. Box DO is located in the center of this region. The mean driving stress of $29.7 \mathrm{kPa}$ for this box is signficantly larger than the average $\tau_{b}$ range of 7.7 to $13.8 \mathrm{kPa}$, which is 
similar to the values inferred for the other tributaries (e.g., $\mathrm{CO}$ and $\mathrm{BT}$ ).

[68] After widening to a maximum width of about $35 \mathrm{~km}$, the main tributary narrows to a width of about $13 \mathrm{~km}$ just upstream of Box UD in Figure 14. For the case with no enhancement, the average basal shear stress over this box is 0.8 to $1.2 \mathrm{kPa}$. This estimate compares well with a measured till strength of $1.0 \pm 0.3 \mathrm{kPa}$ for samples from a borehole at the "UpD" camp [Kamb, 2001], which is located near the center of the downstream edge of Box UD. For the case with enhancement, the mean $\tau_{b}$ estimates of 6.7 to $7.2 \mathrm{kPa}$ are considerably larger than the borehole estimates.

[69] Below the UpD camp, the main trunk of Ice Stream D widens to a width of about $55 \mathrm{~km}$. Box DS includes a large portion of the ice stream trunk and yields a mean $\tau_{b}$ estimate of 3.9 to $4.2 \mathrm{kPa}$ for $E=1$. These estimates are slightly smaller than a force balance estimate of $4.7 \mathrm{kPa}$ that applied to about half the area included in Box DS [Joughin et al., 2002]. The bed beneath the ice stream trunk is not uniformly weak. Basal shear stress is less than $2 \mathrm{kPa}$ for about $35 \%$ of the area within Box DS, but there are also some fairly large $(5-15 \mathrm{~km}$ scale) areas where the bed is signficantly stronger $(10-20 \mathrm{kPa})$. As for the other ice streams, the resolution of the model makes it difficult to tell whether the strong areas are the combined effect of small sticky spots or a broad region of moderately stronger till $(\sim 10 \mathrm{kPa})$. The case with $E=3$ yields similar results, except that the corresponding values are all larger by about 1 to $2 \mathrm{kPa}$.

\subsection{Ice Stream $\mathbf{E}$}

[70] With the exception of the ice plain of Ice Stream B, Ice Stream E, with a width of $70-80 \mathrm{~km}$, is wider than the other active ice streams, which diminishes the influence of lateral drag from its margins. Most of the tributaries feeding the ice stream are shorter and more diffuse than those feeding the other ice streams. Furthermore, these tributaries have much shorter $(<100 \mathrm{~km})$ stretches of weak bed.

[71] The mean driving stress of $21.4 \mathrm{kPa}$ for Box ES in Figure 14 is considerably larger than that of the fast moving regions of Ice Streams B and D. The average $\tau_{b}$ for box ES is $14.8 \mathrm{kPa}$ with an increase of only about $1 \mathrm{kPa}$ when $E$ is increased to 3 . Much of this resistance is concentrated at a few strong sticky spots with $\tau_{b}$ of $20-120 \mathrm{kPa}$. Even the weak areas are, on average, stronger than for the other ice streams with $\tau_{b}$ greater than or equal to $4 \mathrm{kPa}$ for $83 \%$ of Box ES.

[72] The mean $\tau_{b}$ estimate of $14.8 \mathrm{kPa}$ agrees well with earlier control method inversions that yielded a mean value of $14 \mathrm{kPa}$ [MacAyeal et al., 1995]. Even though the mean values agree well, the spatial variability of the results is signifcantly different. The earlier inversions yielded smaller sticky spots in greater numbers, while the results in Figure 14 shows fewer but larger spots. The earlier study was conducted prior to the widespread availabilty of satellite altimeter elevation data. To overcome the poor quality of the data, surface and bed elevations were free parameters in the earlier inversion. The lack of surface elevation data as a constraint on the inversion might explain the differences in spatial structure between the two sets of inversions. It is also important to note that while both studies obtained similar mean $\tau_{b}$ estimates, the earlier study obtained an estimate of $\tau_{d}=49 \mathrm{kPa}$ so that it was concluded that the bed supported only about $30 \%$ of $\tau_{d}$. This is a signficantly different value than our estimate of 69 to $75 \%$ (Table 2) based on our estimate of $\tau_{d}=21.4 \mathrm{kPa}$. We believe that this discrepancy is due to an error in $\tau_{d}$ reported in the previous study [MacAyeal et al., 1995]. This likely mistake was so noted by Raymond [2000]. A reanalysis of the surface and bed elevation fields used in the earlier study suggests that the estimate of $\tau_{d}$ should have been consistent with our estimate.

\section{Discussion}

[73] While consistent with earlier results indicating a weak bed beneath ice streams, the inversions presented above reveal much greater detail with respect to the spatial distribution of the weak-bedded areas at scales greater than a few ice thicknesses. Similarly for the tributaries, although force balance results have suggested the presence of a weak bed [Joughin et al., 2002], the results in Figures 12-14 show far more clearly that tributararies comprise regions of both weak and strong bed.

[74] Beneath the active ice streams, there is a trend toward increasing bed strength from Ice Stream B $(\sim 1$ to $2 \mathrm{kPa})$ then to Ice Stream D $(\sim 4 \mathrm{kPa})$ and finally to Ice Stream E $(\sim 15 \mathrm{kPa})$. An exception to this progression is the area of weak bed just upstream of the main trunk of Ice Stream D $(\sim 1 \mathrm{kPa})$.

[75] Even in the weakest areas, the ice stream beds are not uniformly weak. Excluding Ice Stream E, the fluctuations are reasonably weak with many-ice-thickness-scale regions of basal resistance a few $\mathrm{kPa}$ greater than the mean value. These regions of greater resistance appear to be complemented by regions of very weak $(\sim 0 \mathrm{kPa})$ till. There are several potential causes for the inferred flucutations in bed strength. Till strength is directly proportional to normal effective stress, which is determined by the ice overburden and water pressure [Tulaczyk et al., 2000]. Measured till strengths are consistent with effective normal stresses of $\mathrm{O}(10) \mathrm{kPa}$, so only minor spatial varations in water pressure and ice overburden are required to achieve the inferred spatial variation in $\tau_{b}$ [Tulaczyk et al., 2001]. Such variations could be achieved with only moderate variations in the bed (10's of meters) or surface topography (meters) [Alley, 1993]. Alternatively, seismic observations suggest a small fraction $(3 \%)$ of the bed may be devoid of till beneath Ice Stream B [Rooney et al., 1987]. Basal shear stress for these regions was estimated to be about $44 \mathrm{kPa}$, which averaged over the bed provides a contribution of $1.3 \mathrm{kPa}$ [Alley, 1993]. Thus variability in the density of such till-free areas beneath an ice stream could explain most or all of the inferred few-kPa fluctuations in $\tau_{b}$. A sparse distribution of bedrock bumps could also yield enough form drag to yield fluctuations bed strength of similar magnitude to those we estimate [Alley, 1993].

[76] Earlier studies have indicated that there are weak areas beneath ice stream tributaries [Joughin et al., 2002; Price et al., 2002]. These results were either limited in area or were averaged over large regions and so did not reveal the spatial distribution of bed strength beneath the tributaries. Most of the tribuaries shown in Figures 12, 13, and 14 have alternating regions of weak and strong bed leading up 
to a weak area upstream of the "ice stream onset" (as opposed to the "tributary onset") and the main body of the ice stream. Spacing of these alternating regions is typically about $20-30 \mathrm{~km}$, which is similar to the thickness of extended crust in West Antarctica as well as to spacing of mountain ranges and sedimentary basins in a basin-andrange type of topography [Behrendt, 1999; Studinger et al., 2001]. We speculate that these along-flow variations in bed strength beneath tributaries occur where ice flows across the topographic and tectonic fabric of the underlying extensional terrain. Tributary motion may then be accomplished through a combination of soft-bedded flow over sedimentary basins and hard-bedded flow over mountain ranges.

[77] For well-defined weak areas beneath tributaries, the values for Boxes $\mathrm{BT}, \mathrm{CO}$, and $\mathrm{DO}$ show a relatively consistent range of values ( 7.7 to $12.6 \mathrm{kPa})$. This suggests relatively uniform till properties for the weak regions beneath tributaries (e.g., the dark blue tributary regions in Figures 12, 13, and 14). These weak regions correspond well to relatively well defined areas (e.g, areas bounded by well developed shear margins) where the ice moves at about $80 \mathrm{~m} / \mathrm{yr}$ or faster. Examples of such regions are the tributaries feeding Ice Streams B1 and B2 and the lower portion of Ice Stream D. In contrast, for tributary regions where the bed is stronger and more variable, flow speeds are generally slower $(\sim 50 \mathrm{~m} / \mathrm{yr})$ and flow features are not as sharply defined. Examples of such flow are the upper region of the tributary feeding Ice Stream D and several of the smaller tributaries feeding Ice Stream E. The basal resistance for these slower regions ranges from about 20 to $100 \mathrm{kPa}$. With signficant basal shear stress and sliding (50 to $80 \mathrm{~m} / \mathrm{yr}$ ), these regions may provide an erosional source for the lubricating till [Bell et al., 1998; Joughin et al., 2002].

[78] As discussed earlier, we believe that there is little or no evidence for weakening of ice stream margins based on results from earlier studies and the profiles shown in Figure 9. There remains uncertainty in the degree of uniform strain rate enhancement. The results in Table 2 indicate there is a strong sensitivity $\tau_{b}$ to the enhancment factor. While it depends on the degree of lateral resistance, in general increasing $E$ from 1 to 3 approximately doubles the estimate of $\tau_{b}$. This is a particularly significant effect in the estimation of basal melt rates [Joughin et al., 2003, 2004], since doubling $\tau_{b}$ also doubles the basal shear heating. For instance, Vogel et al. [2003] predicted freezing at the rate of $0-6 \mathrm{~mm} / \mathrm{yr}$ beneath the tributaries of Ice Stream $\mathrm{C}$ by assuming uniform bed strength of $1-10 \mathrm{kPa}$. Using values of $\tau_{b}$ consistent with the results of this inversion, Joughin et al. [2003, 2004] predict basal melting beneath the same tributaries at the rate of a few $\mathrm{mm} / \mathrm{yr}$.

[79] An enhancement factor of 3 is toward the high range of what can be expected for a strong single-maximum fabric [Paterson, 1994]. It is also important to note that in very strong shearing, as in the sides of the ice streams, one does not really expect (nor did Jackson and Kamb [1997] observe) a single-maximum fabric, because recrystallization should actively produce a fabric that is not grossly different in enhancement from random [Alley, 1992]. Thus we believe that the values of $E=1$ and 3 used in the inversions bracket the range of likely values. Figures 12, 13, and 14 show the $\sqrt{J}$ values for both enhancement values. In nearly every case, better results were achieved without enhancement, which suggests that any enhancement is small. The differences are small enough, however, that any minimum of $\sqrt{J}$ with respect to $E$ is likely to be fairly broad.

[80] The boreholes on Ice Stream B are located in a relatively wide region where the lateral resistance is such that $\tau_{b}$ both for the cases with $(\sim 4$ to $6 \mathrm{kPa})$ and without enhancement $(\sim 1$ to $3 \mathrm{kPa})$ are not significantly different than estimates from borehole samples [Kamb, 2001; Tulaczyk et al., 2000]. Furthermore, there is enough spatial variabily that there are large regions for both cases where $\tau_{b} \approx 2 \mathrm{kPa}$, making it difficult to constrain $E$. The region that includes the UD box in Figure 14, however, is located in a much narrower part of the ice stream where the margins provide considerably more resistance. When no enhancement is assumed, the $\tau_{b}$ estimates (0.6 to $\left.1.3 \mathrm{kPa}\right)$ agree well with measurements on till samples $(1.0 \pm 0.3 \mathrm{kPa})$ extracted from a borehole near the lower end of the box [Kamb, 2001]. In constrast, the agreement for $E=3$ is much poorer with mean $\tau_{b}$ estimates of 8.5 to $9.4 \mathrm{kPa}$. Thus the improved agreement with independent observations argues for little or no enhancement.

[81] Laboratory measurements of $E$ have been made using ice extracted from the margin of Ice Stream B [Jackson and Kamb, 1997]. These experiments yielded an enhancement factor of $\sim 1.2$ relative to the temperature dependent parameterization for $A(B)$ used in our inversions. This is consistent with the improved model fits and the better agreement of the inversions at the borehole on Ice Stream D. Thus our preferred solution for the inversions is that with $E=1$, with the acknowledgement that there may be some minor enhancement $(\sim 1.2)$ not included in the model. It is important to note that many of the data used for determining the temperature dependence of the flow law at temperatures less than $-10^{\circ} \mathrm{C}$ were obtained from observational data on the spreading of ice shelves [Paterson, 1994]. The resulting parameterization for the flow law yields values of $A$ up to $60 \%$ greater than suggested by some lab measurements [Paterson, 1994]. Thus, even with a value of $E=1$ some degree of strain rate enhancement may be implicitly included in the flow law parameterization that we used for the inversions.

\section{Summary}

[82] We have revisited the use of control method inversions, which were developed more than a decade ago, to determine the basal shear stress beneath ice streams where new high-resolution velocity data sets have recently become available. In an effort to better understand the performance characteristics of the inversion procedures, we have conducted several experiments with synthetic ice stream data where we could compare the inferred basal shear stress against the known solution. These experiments show that when better surface elevation data are available, ice stream velocities can be used to yield reasonable estimates of basal shear stress at scales greater than a few ice thicknesses. Remaining uncertainty in the flow law parameters contributes to the uncertainy in our inversions. The results suggest that the overall degree of flow enhancement is small. Unlike direct force balance methods, the smoothing properties of 
the control method inversions make the results relatively insensitive to the typical noise levels encountered with InSAR data. Some regions on Ice Streams A and B yielded relatively poor quality inversions due to the low quality of the surface elevation data. We expect that signicantly better results will be achieved in these regions once improved elevation data are available from the Geoscience Laser Altimeter System (GLAS).

[83] We performed inversions covering the major Ross ice streams and their tributaries. Consistent with interpretations based on the sparse sampling of the borehole and seismic data, we find that ice streams lie atop a bed that is nearly everywhere weak. The results suggest that there may be variation of a few $\mathrm{kPa}$, arising from any of several sources of resistance (e.g., pressure fluctuations, till free patches, form drag) at scales of a few ice thicknesses. The results are consistent with a fairly uniform drape of dilatant till beneath the ice streams.

[84] The ice stream tributaries lie atop a bed with alternating patches of strong and weak bed. In the areas where the tributary beds appear weak, the inferred basal shears stresses $(\sim 8$ to $12 \mathrm{kPa})$ are slightly higher than typical ice stream values $(\sim 2 \mathrm{kPa})$. The regions where the tributary beds are relatively strong $(>20 \mathrm{kPa})$ suggest areas with the potential for enhanced melt and erosion due to the increased basal friction.

[85] Our inversions are based on a single map of velocity that, for the most part, was collected over a 30-day period. The inversions yield estimates of the basal shear stress that balance forces to match these observations. Either a plastic or viscous till rheology appears to be consistent with the inferred basal-shear-stress distribution. This implies that a determination of the appropriate till rheology (e.g., plastic or viscous) from these experiments is not possible. Any perturbation of this balance of forces (e.g., driving stress or basal shear stress) will yield a new velocity distribution and a resulting new force balance, depending on the rheological properties of the till. Thus a measured time series of velocity change, such as those recently acquired on Ice Streams B and D [Anandakrishnan et al., 2003; Bindschadler et al., 2003], may be what is ultimately needed to determine whether the till beneath the Ross ice streams acts viscously or plastically at all spatial scales [Hindmarsh, 1997].

[86] Acknowledgments. I. Joughin performed his contribution to this work at the Jet Propulsion Laboratory, California Institute of Technology, under contract with National Aeronautics and Space Administration. S. Tulaczyk was funded by a grant from National Aeronautics and Space Administration. The revised manuscript was signficantly improved by comments from R. Alley and an anonymous reviewer. The RADARSAT data were acquired by the Canadian Space Agency and were downlinked and processed to L0-products by the Alaska SAR Facility. Mosaicked RADARSAT images and the surface DEM were provided by K. Jezek of the Byrd Polar Research Center. D. G. Vaughan and the BEDMAP project produced the bed topography DEM. Many of the data sets we used were archived and distributed by the National Snow and Ice Data Center (NSIDC).

\section{References}

Alley, R. B. (1992), Flow-law hypotheses for ice-sheet modeling, J. Glaciol., 38(129), 245-256.

Alley, R. B. (1993), In search of ice-stream sticky spots, J. Glaciol., 39(133), 447-454.

Alley, R. B., D. D. Blankenship, C. R. Bentley, and S. T. Rooney (1986), Deformation of till beneath Ice Stream-B, West Antarctica, Nature, 322(6074), 57-59.
Anandakrishnan, S. (2003), Dilatant till layer near the onset of streaming flow of Ice Stream C, determined by AVO (amplitude vs. offset) analysis, Ann. Glaciol., 36, 283-286.

Anandakrishnan, S., D. D. Blankenship, R. B. Alley, and P. L. Stoffa (1998), Influence of subglacial geology on the position of a West Antarctic ice stream from seismic observations, Nature, 394(6688), $62-65$.

Anandakrishnan, S., D. E. Voigt, R. B. Alley, and M. A. King (2003), Ice stream D flow speed is strongly modulated by the tide beneath the Ross Ice Shelf, Geophys. Res. Lett., 30(7), 1361, doi:10.1029/2002GL016329.

Behrendt, J. C. (1999), Crustal and lithospheric structure of the West Antarctic Rift System from geophysical investigations-A review, Global Planet Change, 23(1-4), 25-44.

Bell, R. E., D. D. Blankenship, C. A. Finn, D. L. Morse, T. A. Scambos, J. M. Brozena, and S. M. Hodge (1998), Influence of subglacial geology on the onset of a West Antarctic ice stream from aerogeophysical observations, Nature, 394(6688), 58-62.

Bindschadler, R., P. Vornberger, D. Blankenship, T. Scambos, and R. Jacobel (1996), Surface velocity and mass balance of Ice Streams D and E, West Antarctica, J. Glaciol., 42(142), 461-475.

Bindschadler, R., P. L. Vornberger, M. King, and L. Padman (2003), Diurnal stick-slip motion in the mouth of Whillans Ice Stream, Ann. Glaciol., 36, 263-272.

Blankenship, D. D., C. R. Bentley, S. T. Rooney, and R. B. Alley (1986), Seismic measurements reveal a saturated porous layer beneath an active Antarctic ice stream, Nature, 322(6074), 54-57.

Blankenship, D. D. D. L. Morse, C. A. Finn, R. E. Bell, M. E. Peters, S. D. Kempf, S. M. Hodge, M. Studinger, J. C. Behrendt, and J. M. Brozena (2001), Geologic controls on the initiation of rapid basal motion for West Antarctic Ice Streams: A geophysical perspective including new airborne radar sounding and laser altimetry results, in The West Antarctic Ice Sheet: Behavior and Environment, Antarct. Res. Ser., vol. 77, edited by R. B. Alley and R. A. Bindschadler, pp. 105-122, AGU, Washington, D. C.

Clark, P. U., R. B. Alley, and D. Pollard (1999), Northern Hemisphere icesheet influences on global climate change, Science, 286(5442), 11041111.

Conway, H., B. L. Hall, G. H. Denton, A. M. Gades, and E. D. Waddington (1999), Past and future grounding-line retreat of the West Antarctic Ice Sheet, Science, 286(5438), 280-283.

Echelmeyer, K. A., W. D. Harrison, C. Larsen, and J. E. Mitchell (1994), The role of the margins in the dynamics of an active ice stream, J. Glaciol., 40(136), 527-538.

Fahnestock, M. A., T. A. Scambos, R. A. Bindschadler, and G. Kvaran (2000), A millennium of variable ice flow recorded by the Ross Ice Shelf, Antarctica, J. Glaciol., 46(155), 652-664.

Gray, A. L., K. E. Mattar, and G. Sofko (2000), Influence of ionospheric electron density fluctuations on satellite radar interferometry, Geophys. Res. Lett., 27(10), 1451-1454.

Gudmundsson, G. H., C. F. Raymond, and R. Bindschadler (1998), The origin and longevity of flow stripes on Antarctic ice streams, Ann. Glaciol., 27, 145-152.

Harrison, W. D., K. A. Echelmeyer, and C. F. Larsen (1998), Measurement of temperature in a margin of Ice Stream B, Antarctica: Implications for margin migration and lateral drag, J. Glaciol., 44(148), 615-624.

Hindmarsh, R. (1997), Deforming beds: Viscous and plastic scales of deformation, Quat. Sci.Rev., 16(9), 1039-1056.

Hulbe, C. L., I. R. Joughin, D. L. Morse, and R. A. Bindschadler (2000), Tributaries to West Antarctic ice streams: Characteristics deduced from numerical modelling of ice flow, Ann. Glaciol., 31, 184-190.

Jackson, M., and B. Kamb (1997), The marginal shear stress of Ice Stream B, West Antarctica, J. Glaciol., 43(145), 415-426.

Jezek, K. C. (2002), RADARSAT-1 Antarctic Mapping Project: Changedetection and surface velocity campaign, Ann. Glaciol., 34, 263-268.

Joughin, I., and S. Tulaczyk (2002), Positive mass balance of the Ross ice streams, West Antarctica, Science, 295(5554), 476-480.

Joughin, L., L. Gray, R. Bindschadler, S. Price, D. Morse, C. Hulbe, K. Mattar, and C. Werner (1999), Tributaries of West Antarctic Ice streams revealed by RADARSAT interferometry, Science, 286(5438), 283-286.

Joughin, I. R., M. A. Fahnestock, and J. L. Bamber (2000), Ice flow in the northeast Greenland ice stream, in Ann. Glaciol., 31, 141-146.

Joughin, I., S. Tulaczyk, R. Bindschadler, and S. F. Price (2002), Changes in West Antarctic ice stream velocities: Observation and analysis, J. Geophys. Res., 107(B11), 2289, doi:10.1029/2001JB001029.

Joughin, I., S. Tulaczyk, and H. F. Engelhardt (2003), Basal melt beneath Whillans Ice Stream and Ice Streams A and C, Ann. Glaciol., 36, 257262

Joughin, I., S. Tulaczyk, D. R. MacAyeal, and H. Engelhardt (2004), Basal melting and freezing beneath the Ross ice streams, Antarctica, J. Glacol., in press. 
Kamb, B. (1991), Rheological nonlinearity and flow instability in the deforming bed mechanism of ice stream motion, J. Geophys. Res., 96(B10), $16,585-16,595$

Kamb, B. (2001), Basal zone of the West Antarctic ice streams and its role in lubrication of their rapid motion, in The West Antarctic Ice Sheet: Behavior and Environment, Antarct. Res. Ser., vol. 77, edited by R. B. Alley and R. A. Bindschadler, pp. 157-199, AGU, Washington, D. C.

Liu, H. X., K. C. Jezek, and B. Y. Li (1999), Development of an Antarctic digital elevation model by integrating cartographic and remotely sensed data: A geographic information system based approach, J. Geophys. Res., 104(B10), 23,199-23,213

Lythe, M. B., and D. G. Vaughan (2001), BEDMAP: A new ice thickness and subglacial topographic model of Antarctica, J. Geophys. Res., 106(B6), 1335-1351

MacAyeal, D. R. (1989), Large-scale ice flow over a viscous basal sediment: Theory and application to Ice Stream B, Antarctica, J. Geophys. Res., 94(B4), 4071-4087.

MacAyeal, D. R. (1992), The basal stress distribution of Ice Stream E, Antarctica, inferred by control methods, J. Geophys. Res., 97(B1), $595-603$

MacAyeal, D. R. (1993), A tutorial on the use of control methods in icesheet modeling, J. Glaciol., 39(131), 91-98.

MacAyeal, D. R., R. A. Bindschadler, and T. A. Scambos (1995), Basal friction of Ice-Stream-E, West Antarctica, J. Glaciol., 41(138), 247-262.

Paterson, W. S. B. (1994), The Physics of Glaciers, 3rd ed., 480 pp., Pergamon, New York.

Price, S. F., R. A. Bindschadler, C. L. Hulbe, and D. D. Blankenship (2002), Force balance along an inland tributary and onset to Ice Stream D, West Antarctica, J. Glaciol., 48(160), 20-30.

Raymond, C. (1996), Shear margins in glaciers and ice sheets, J. Glaciol. 42(140), 90-102.

Raymond, C. F. (2000), Energy balance of ice streams, J. Glaciol., 46(155), $665-674$

Retzlaff, R., and C. R. Bentley (1993), Timing of stagnation of Ice StreamC, West Antarctica, from short-pulse radar studies of buried surface crevasses, J. Glaciol., 39(133), 553-561.

Retzlaff, R., N. Lord, and C. R. Bentley (1993), Airborne-radar studies Ice Streams A, B and C, West Antarctica, J. Glaciol., 39(133), 495 506
Rooney, S. T., D. D. Blankenship, R. B. Alley, and C. R. Bentley (1987), Till beneath ice stream-B: 2. Structure and continuity, J. Geophys. Res., 92(B9), 8913-8920.

Studinger, M., R. E. Bell, D. D. Blankenship, C. A. Finn, R. A. Arko, D. L. Morse, and I. Joughin (2001), Subglacial sediments: A regional geological template for ice flow in West Antarctica, Geophys. Res. Lett., 28(18), 3493-3496.

Thomas, R. H., D. R. MacAyeal, C. R. Bentley, and J. L. Clapp (1980), The creep of ice, geothermal heat flow, and Roosevelt Island, Antarctica, J. Glaciol., 25(91), 47-60.

Thorsteinsson, T., C. F. Raymond, G. H. Gudmundsson, R. Bindschadler, P. Vornberger, and I. Joughin (2004), Bed topography and lubrication inferred from surface measurements on fast flowing ice streams, J. Glaciol., in press.

Tulaczyk, S., W. B. Kamb, and H. F. Engelhardt (2000), Basal mechanics of Ice Stream B, West Antarctica: 1. Till mechanics, J. Geophys. Res., 105(B1), 463-481.

Tulaczyk, S., B. Kamb, and H. F. Engelhardt (2001), Estimates of effective stress beneath a modern West Antarctic ice stream from till preconsolidation and void ratio, Boreas, 30(2), 101-114.

Van der Veen, C. J. (1999), Fundamentals of Glacier Dynamics, 462 pp., A. A. Balkema, Brookfield, Vt.

Vogel, S. W., S. Tulaczyk, and I. R. Joughin (2003), Distribution of basal melting and freezing beneath tributaries of Ice Stream C: Implication for the Holocene decay of the West Antarctic Ice Sheet, Ann. Glaciol., 36, $273-282$.

Whillans, I. M., and C. J. van der Veen (1997), The role of lateral drag in the dynamics of Ice Stream B, Antarctica, J. Glaciol., 43(144), 231-237.

I. Joughin, Polar Science Center, Applied Physics Laboratory, University of Washington, 1013 NE 40th Street, Seattle, WA 98105-6698, USA. (ian@apl.washington.edu)

D. R. MacAyeal, Department of Geophysical Sciences, University of Chicago, 5734 S. Ellis Avenue, Chicago, IL 60637, USA. (drm7@midway. uchicago.edu)

S. Tulaczyk, Earth Sciences Department, A208 Earth and Marine Sciences Building, University of California, Santa Cruz, CA 95064, USA. (tulaczyk@es.ucsc.edu) 